\title{
The Role of Moisture in Summertime Low-Level Jet Formation and Associated Rainfall over the East Asian Monsoon Region
}

\author{
RUIDAN CHEN \\ State Key Laboratory of Numerical Modeling for Atmospheric Sciences and Geophysical Fluid Dynamics, Institute of \\ Atmospheric Physics, Chinese Academy of Sciences, and University of Chinese Academy of Sciences, Beijing, \\ China, and Max Planck Institute for Meteorology, Hamburg, Germany \\ LORENZO TOMASSINI \\ Max Planck Institute for Meteorology, Hamburg, Germany
}

(Manuscript received 3 March 2015, in final form 17 June 2015)

\begin{abstract}
The southwesterly low-level jet (LLJ) located to the east of the Tibetan Plateau in southern China plays an important role in summertime convective initiation over north China. This study adopts a novel perspective and uses hindcast experiments in order to investigate the role of moisture in LLJ and associated heavy rainfall formation, employing a global atmospheric general circulation model (AGCM). In the sensitivity experiments, an increase of humidity in the inflow region leads to a weaker LLJ but stronger diurnal wind oscillations. The weaker LLJ is due to a decreased lower-tropospheric east-west pressure gradient resulting from a low pressure anomaly over southeastern China induced by deep convection and related condensational heating. On the other hand, the stronger diurnal variation of the LLJ originates from stronger day-and-night thermal differences over the sloping terrain, which is related to drier conditions over the mountain range. Moreover, the increased humidity and decreased LLJ counteract one another to impact precipitation in the outflow region. The change of precipitation is mainly determined by the altered moisture flux divergence. If the increase in humidity dominates, then the moisture flux convergence is enhanced and favors more precipitation over north China. Otherwise, if the decreased LLJ dominates, then the moisture flux convergence is reduced, which constrains precipitation. It is highlighted that the moist diabatic and dynamic processes are intimately coupled, and that a correct simulation of moisture flux convergence is vital for AGCMs to reproduce the LLJ-related precipitation, particularly the nocturnal precipitation peak, which is a deficiency in many current models.
\end{abstract}

\section{Introduction}

During Northern Hemisphere summertime, as the East Asian monsoon migrates northward, a southwesterly low-level jet (LLJ) frequently establishes to the east of the Tibetan Plateau. The LLJ feeds moisture to mesoscale convective systems and transports high moist static energy air to precipitation regions in north China (Wang et al. 2013).

The different stages of the East Asian summer monsoon (EASM) are intimately connected with the northward movement of the western Pacific subtropical

Corresponding author address: Ruidan Chen, Institute of Atmospheric Physics, Chinese Academy of Sciences, Chao Yang District, P.O. Box 9804, Beijing 100029, China.

E-mail: crd@lasg.iap.ac.cn high (WPSH) and a deepening and northward displacement of the heat low from southern to central China (e.g., Saha 2010). The pressure gradient between the WPSH and the heat low produces strong low-level baroclinicity and provides the geostrophic forcing for the LLJ (Stensrud 1996). Moreover, the day-and-night thermal differences over sloping terrain lead to diurnal oscillations of local pressure gradients and baroclinicity, which induce upslope and downslope winds and give rise to diurnal variations of the LLJ (Holton 1967; Jiang et al. 2007).

There is extensive literature on LLJs in different regions of the world. While the detailed processes leading to LLJs within the EASM are less investigated (Liu et al. 2014), numerous works deal with the LLJ over the Great Plains to the east of the Rocky Mountains (e.g., Bonner 1968; Jiang et al. 2007) and the flat region east of the 
Andes in South America (e.g., Saulo et al. 2007). Past studies mostly focused on formation mechanisms and the role of the LLJ in transporting moisture and promoting the onset of precipitation. Despite substantial advances in the field, and an improved conceptual understanding of LLJs, major questions remain open. For instance, Is the obvious connection between LLJs and nighttime deep convection and related precipitation mainly caused by convergence and mechanical lifting of air? Or, a result of the increased low-level abundance of high moist static energy accumulated by the LLJ and consequent atmospheric instability? Or, a result of other mechanisms that promote moisture convergence? Why do atmospheric general circulation models (AGCMs) reproduce the characteristics of the LLJ well but miss to simulate the nocturnal peak in precipitation over the LLJ exit region (Jiang et al. 2007)?

The present study adopts a different perspective and asks, what is the influence of moisture on the LLJ and related rainfall in the EASM system? The traditional view on this question suggests that increased moisture content implies enhanced moisture transport by the low-level jet and consequently more vigorous precipitation at the LLJ outflow area. However, as pointed out by earlier studies that focused on the mechanisms that control the regional monsoon circulation, condensational heating — and thus moisture-plays an important role in setting pressure gradients and the baroclinic structure within the EASM (Wang and Orlanski 1987; Jin et al. 2013). Here we use a global AGCM in forecast mode and examine the role of moisture in two selected heavy rainfall events by varying the initial humidity content of the atmosphere. It is demonstrated that the effect of condensational heating on the EASM circulation-and hence the LLJ-is a decisive component in regulating the regional moisture transport and precipitation pattern.

Hindcast experiments have traditionally been used to identify weather or climate model biases (e.g., Medeiros et al. 2012; Williams et al. 2013). Here we show that this framework allows not only for elucidating the local formation mechanism of the LLJ but also for studying the interaction of diabatic moist processes and the divergent large-scale circulation. An advantage of using hindcast simulations of real cases over more idealized approaches (e.g., Booth et al. 2013) for this purpose is the possibility of benefiting from observations in order to assess the model behavior.

The question about the role of moisture and moisture transport within the EASM, and within monsoon systems located at precipitation margins in general, is important also in a broader context. In a warmer world the atmosphere can hold larger amounts of moisture, and the ability of models to resolve moisture transport is crucial when it comes to correctly reproduce trends in water vapor and clouds, particularly in regions of large relative humidity gradients (Sherwood et al. 2010). It is therefore paramount to better understand the regional interaction of moisture transport, diabatic processes, and the atmospheric circulation in order to more reliably simulate potential future changes in regional precipitation patterns.

The reminder of the paper is divided into seven sections. The atmospheric model, observational data, and experimental setup are presented in section 2. In section 3 it is shown that the model is able to reproduce the atmospheric conditions as prevalent during the first selected case of LLJ development and subsequent heavy rainfall on 30 July 2007. Section 4 covers the investigation of the impact of moisture on the LLJ formation for the case on 30 July 2007. The role of moisture transport for precipitation in the LLJ exit region is analyzed in section 5 for the same case. Section 6 includes a brief discussion of the main difference between the second case on 21 July 2012 and the first case, and is followed by conclusions in section 7 .

\section{Model and experiments}

\section{a. Atmospheric model}

For the present study, the atmospheric general circulation model ECHAM6.2.0 is used in its high-resolution configuration T127 with 95 vertical levels. ECHAM6 employs a slightly modified version of the TiedtkeNordeng convection scheme (Tiedtke 1989; Nordeng 1994) that is thoroughly discussed in Möbis and Stevens (2012). The boundary layer parameterization consists of a turbulent kinetic energy scheme modified from that described by Brinkop and Röckner (1995).

Compared to the ECHAM6 version portrayed in Stevens et al. (2013), ECHAM6.2.0 includes major bug fixes that are related to mass and energy conservation in different physical parameterizations, and the removal of a faulty implementation of the cloud cover scheme that effectively hindered the occurrence of partial cloud cover in the previous version of the model. Moreover, radiative transfer is now computed using radiative codes called PSrad (Pincus and Stevens 2013), a two-stream model that descends from the RRTM for GCMs (RRTMG) codes (Mlawer et al. 1997; Iacono et al. 2008) developed by Atmospheric and Environmental Research (AER). The advantage of using a global GCM rather than a limited-area model is that the atmospheric dynamics of the global model is free to evolve in the performed hindcast experiments and is not constrained by lateral boundary conditions. This allows for investigating the 
interaction between diabatic moist processes and the atmospheric circulation.

\section{b. LLJ definition, observational data, and experiments}

In the following a definition of an LLJ as proposed by Bonner (1968) is adopted [see also Stensrud (1996) for a discussion of various definitions]. More precisely, an LLJ is identified at a particular location and time if (i) there is a local wind speed maximum in the vertical below $700 \mathrm{hPa}$ (including $700 \mathrm{hPa}$ ) that exceeds $8 \mathrm{~m} \mathrm{~s}^{-1}$; (ii) the local wind speed maximum is at least $4 \mathrm{~ms}^{-1}$ larger than the minimum wind speed in the above layers; and (iii) the wind direction is southwesterly, that is, between $180^{\circ}$ and $270^{\circ}$. The last criterion is introduced as in Wang et al. (2013) because we are interested in the southwesterly moisture transport by the LLJ and associated precipitation formation in north China.

Observational rainfall data are used from the $1^{\circ}$, daily dataset of the Global Precipitation Climatology Project (GPCP) for the period 1997-2012 (Huffman et al. 2001), and the 3-hourly Tropical Rainfall Measuring Mission (TRMM) dataset (Huffman et al. 2007).

To investigate the influence of moisture on the LLJ and its impact on the associated moisture transport and precipitation formation in the outflow region of the jet, we select two events that were characterized by heavy precipitation in north China: one on 30 July 2007 and one on 21 July 2012. During these 2 days the largest rainfall in the area $35^{\circ}-42^{\circ} \mathrm{N}, 110^{\circ}-117^{\circ} \mathrm{E}$ (shown as the smaller box over north China in Fig. 1) exceeds the 99.9\% quantile of rainfall from all the GPCP grid points in this region over the period 1997-2012 in the GPCP daily precipitation data. Moreover, there was widespread occurrence of LLJs during the 2 days before these rainfall events over southern China (shown as the bigger box in Fig. 1).

For the two selected events, 5-day hindcast experiments were performed. The AGCM was initialized 2 days before the events at 0000 UTC. Daily sea surface temperatures from ERA-Interim (Dee et al. 2011) were prescribed. To obtain suitable initial conditions for the hindcast experiments, the AGCM was nudged toward ERA-Interim using a Newtonian relaxation scheme starting from 1 January of the respective year until the start date of the hindcast experiment. Only winds, surface pressure, and temperature are nudged, not humidity. These standard hindcast simulations are referred to as Q1.0 experiments in the following.

Sensitivity experiments were conducted by increasing the initial specific humidity of the hindcast simulations in the lower troposphere over the inflow region of the LLJ. More specifically, the initial specific humidity within
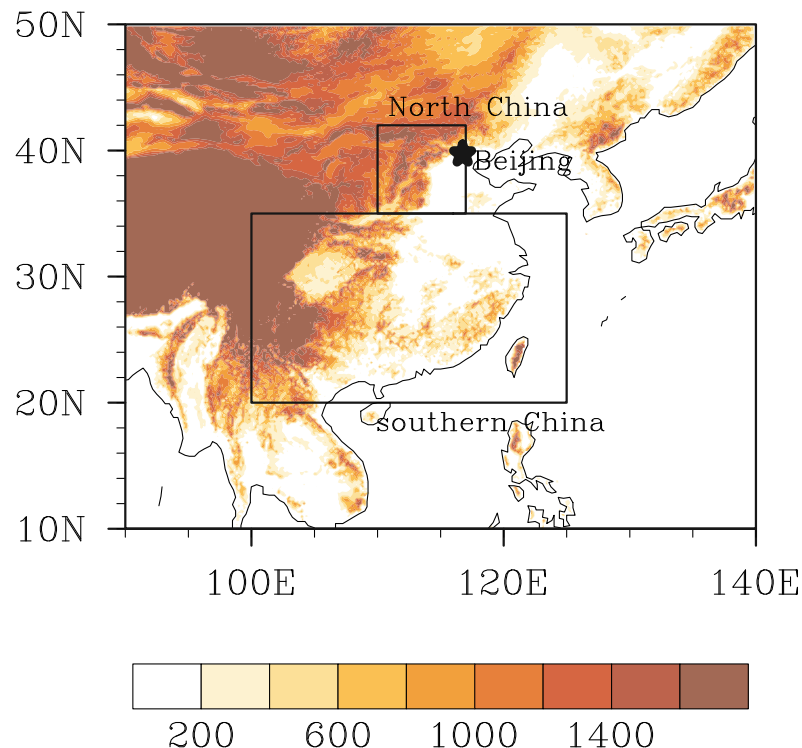

FIG. 1. The studied domains and topography: the smaller box $\left(35^{\circ}-42^{\circ} \mathrm{N}, 110^{\circ}-117^{\circ} \mathrm{E}\right)$ over north China denotes the areas contained to define heavy precipitation; and the larger box $\left(20^{\circ}-35^{\circ} \mathrm{N}\right.$, $100^{\circ}-125^{\circ} \mathrm{E}$ ) over southern China denotes the areas used to define LLJ. The black star denotes the location of Beijing. The shaded contours denote elevations $(\mathrm{m})$.

the box $20^{\circ}-30^{\circ} \mathrm{N}, 110^{\circ}-120^{\circ} \mathrm{E}$ is increased by an amplitude of $50 \%$ below $650 \mathrm{hPa}$, and the amplitude is linearly decreased over the box boundaries (see also Fig. 5). It was checked that the relative humidity does not exceed $100 \%$ in any grid box and at any height level. These sensitivity experiments are denoted by Q1.5 for short.

An additional, slightly modified experiment in which the specific humidity is increased below $300 \mathrm{hPa}$ produced very similar results as the Q1.5 experiment, confirming that the lower-, not the upper-, tropospheric humidity is decisive for our problem. We therefore restrict the analysis to the Q1.5 experiment.

In the following sections, the event on 30 July 2007 is described and analyzed in detail. In section 6 the event on 21 July 2012 is discussed and compared with the first event before presenting conclusions. We also considered other joint occurrences of heavy rainfall and LLJs during the period from 1997 to 2012 and found that the mechanisms at work in other events were a mixture of the two prototypes described in the present paper. For reasons of clarity of presentation we therefore decided to restrict the discussion to the two aforesaid events.

\section{Simulated LLJ and precipitation}

In this section the standard simulation Q1.0 of the 30 July 2007 event is compared with reanalysis and observations. Spinup effects are disregarded and the model 
output of the second forecast day (29 July 2007) — that is, 24-48 h after initialization-is used for the evaluation. The Q1.0 experiment reproduces well the LLJ with strong lower-tropospheric southwesterlies (Fig. 2a). The region that meets the LLJ definition (shaded areas) is located near $110^{\circ} \mathrm{E}$ from about $25^{\circ}$ to $40^{\circ} \mathrm{N}$. Strong southwesterlies and southerlies occur along the jet and extend northward to almost $50^{\circ} \mathrm{N}$. This indicates that the LLJ is already well developed one day before the heavy precipitation event and transports moisture from the south to the outflow regions. In ERA-Interim, there is also an LLJ near $110^{\circ} \mathrm{E}$ (Fig. 2b), but it is somewhat less widespread compared to Q1.0. Overall, the model well captures the LLJ location and the associated strong southwesterlies and southerlies.

The pattern of 850-hPa geopotential height is consistent with the winds. In Q1.0 there is high pressure east of $110^{\circ} \mathrm{E}$ and low pressure west of $110^{\circ} \mathrm{E}$ (Fig. 2c). The high pressure is associated with the western Pacific subtropical high. The 1460 -gpm isoline near $110^{\circ} \mathrm{E}$ shows a southwest-northeast orientation from $25^{\circ}$ to $50^{\circ} \mathrm{N}$. Figures $2 \mathrm{a}$ and $2 \mathrm{c}$ confirm that strong southwesterlies and southerlies prevail in the area together with a distinct east-west pressure gradient. This suggests that the LLJ is geostrophic to first order, consistent with previous studies (e.g., Cook and Vizy 2010). The major features of 850-hPa geopotential height in ERA-Interim are similar (Fig. 2d): there is high pressure east of $110^{\circ} \mathrm{E}$ and low pressure west of $110^{\circ} \mathrm{E}$. However, the 1460 -gpm isoline near $110^{\circ} \mathrm{E}$ exhibits a southwest-northeast orientation from $25^{\circ}$ to $35^{\circ} \mathrm{N}$, and then it turns to a southeast-northwest orientation north of $35^{\circ} \mathrm{N}$. Thus, compared to Q1.0, in ERA-Interim the east-west pressure gradient north of $35^{\circ} \mathrm{N}$ is smaller and the horizontal winds are weaker (Fig. 2b).

The main features of air temperature and specific humidity in Q1.0 are also similar to ERA-Interim (Figs. 2e-h). Both data show high humidity areas along the position of the LLJ, confirming the importance of the LLJ in transporting moisture. The specific humidity at $850 \mathrm{hPa}$ along the jet is somewhat higher in Q1.0 than in ERA-Interim, which is related to the more distinct LLJ in Q1.0. As a whole, the model hindcast well reproduces the horizontal structure of winds, geopotential height, temperature and specific humidity.

To evaluate the vertical structure of the LLJ, zonal sections of horizontal wind speeds averaged from $25^{\circ}$ to $30^{\circ} \mathrm{N}$ are shown (Fig. 3). In Q1.0 there is a maximum wind speed center in the lower troposphere over $110^{\circ} \mathrm{E}$, with maximum amplitude of over $12 \mathrm{~ms}^{-1}$ (Fig. 3a). Above the maximum center, the wind speed decreases upward and becomes about $8 \mathrm{~m} \mathrm{~s}^{-1}$ in the middle and upper troposphere, demonstrating a clear vertical wind shear. In addition, the LLJ is located to the east of Tibetan Plateau, indicating that the LLJ formation is closely related to a blocking effect caused by the topography (Jiang et al. 2007). The vertical structure of the LLJ in ERA-Interim is very similar, with a maximum wind speed center in the lower troposphere and clear vertical wind shear over $110^{\circ} \mathrm{E}$ (Fig. 3b). However, in ERA-Interim the lower-tropospheric maximum wind speed occurs in lower layers. The similarities between Q1.0 and ERA-Interim confirm that the model is capable of simulating the 3D structure of the LLJ, underpinning the validity of our approach.

Figure 4 displays daily precipitation totals on $30 \mathrm{July}$, the day of the heavy rainfall, from Q1.0, ERA-Interim reanalysis, and observations (both GPCP and TRMM). In Q1.0 precipitation occurs along the LLJ, mainly located near $110^{\circ} \mathrm{E}$ from $25^{\circ}$ to $40^{\circ} \mathrm{N}$ in the southwestnortheast direction, with a maximum center located to the southwest of north China (Fig. 4a). In contrast, the precipitation in both reanalysis and observations show maximum centers in the LLJ outflow regions over north China, located around $34^{\circ}-44^{\circ} \mathrm{N}, 110^{\circ}-120^{\circ} \mathrm{E}$ (Figs. 4b-d). The heavy precipitation concentrates around Beijing, China $\left(39.8^{\circ} \mathrm{N}, 116.75^{\circ} \mathrm{E}\right)$, indicated by the black star in Fig. 1, with maximum amplitudes of over $20 \mathrm{~mm} \mathrm{day}^{-1}$ in ERA-Interim, and over $50 \mathrm{~mm} \mathrm{day}^{-1}$ in GPCP and TRMM. Thus the reanalysis reproduces the correct precipitation center, although with smaller amplitude. A decomposition of total precipitation into convective precipitation and large-scale precipitation indicates that the majority of precipitation is associated with convective activities (not shown). The model simulation misses the heavy convective precipitation maximum at the LLJ exit region, which is partly related to the different structure of the pressure field in north China compared to the reanalysis (Figs. 2c,d).

\section{Impact of moisture on LLJ}

Sensitivity experiments, named Q1.5, in which the initial specific humidity in the LLJ inflow region is increased, are conducted to investigate the role of moisture in the LLJ and precipitation formation. The temporal development of the differences in specific humidity between Q1.5 and Q1.0 are shown in Fig. 5 (hereafter, the differences denote Q1.5 - Q1.0 unless mentioned otherwise). The differences at the first forecast hour indicate the perturbation of initial conditions in Q1.5 (Figs. 5a,b). In the horizontal, the specific humidity within the box $20^{\circ}-30^{\circ} \mathrm{N}, 110^{\circ}-120^{\circ} \mathrm{E}$ is increased by $50 \%$, and then the increased amplitudes gradually decrease over the box boundaries. In the vertical, the 
(a) Q1.0

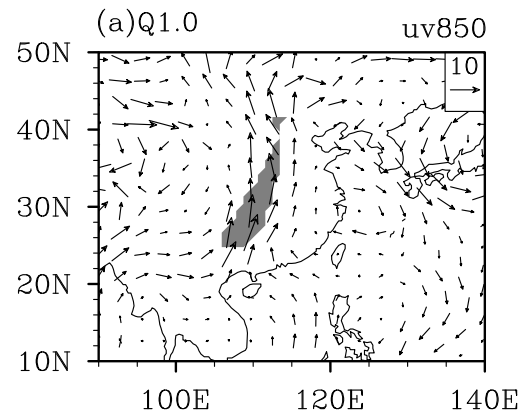

(c) Q1.0
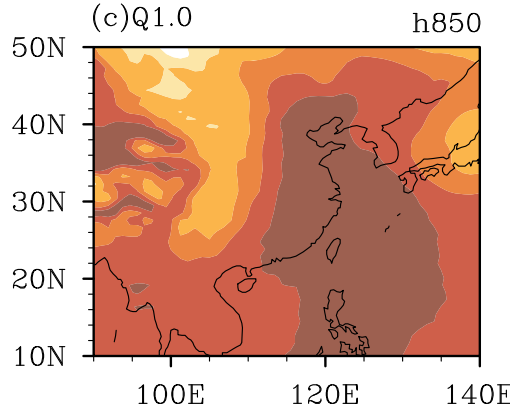

$100 \mathrm{E}$

14201440146014801500
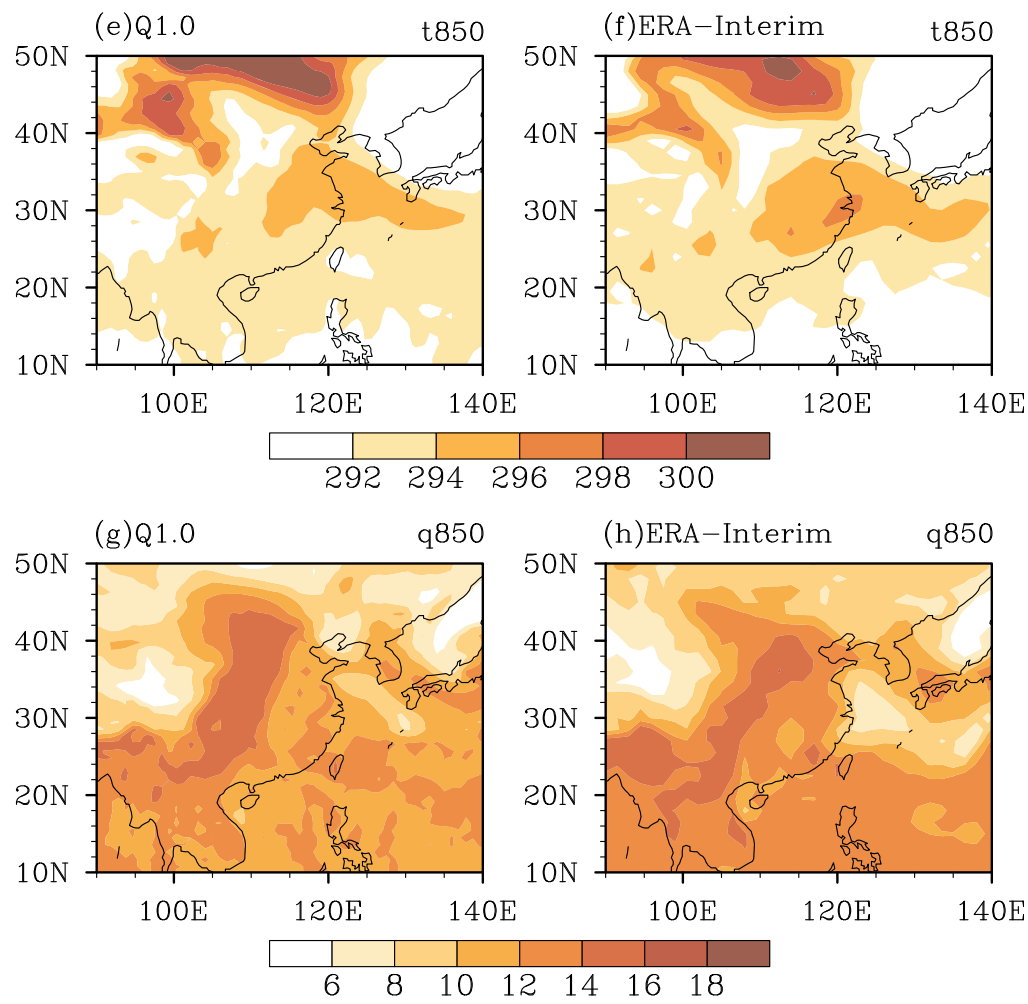

FIG. 2. Comparisons of the simulations of large-scale circulation from the (a),(c), (e),(g) standard experiments (Q1.0) and (b),(d),(f),(g) ERA-Interim on 29 Jul 2007 of $850-\mathrm{hPa}(\mathrm{a})$,(b) wind vectors $\left(\mathrm{m} \mathrm{s}^{-1}\right.$; shading denotes the areas meeting the definition of LLJ); (c),(d) geopotential height (gpm); (e),(f) air temperature (K); and (g), (h) specific humidity $\left(\mathrm{g} \mathrm{kg}^{-1}\right)$. 


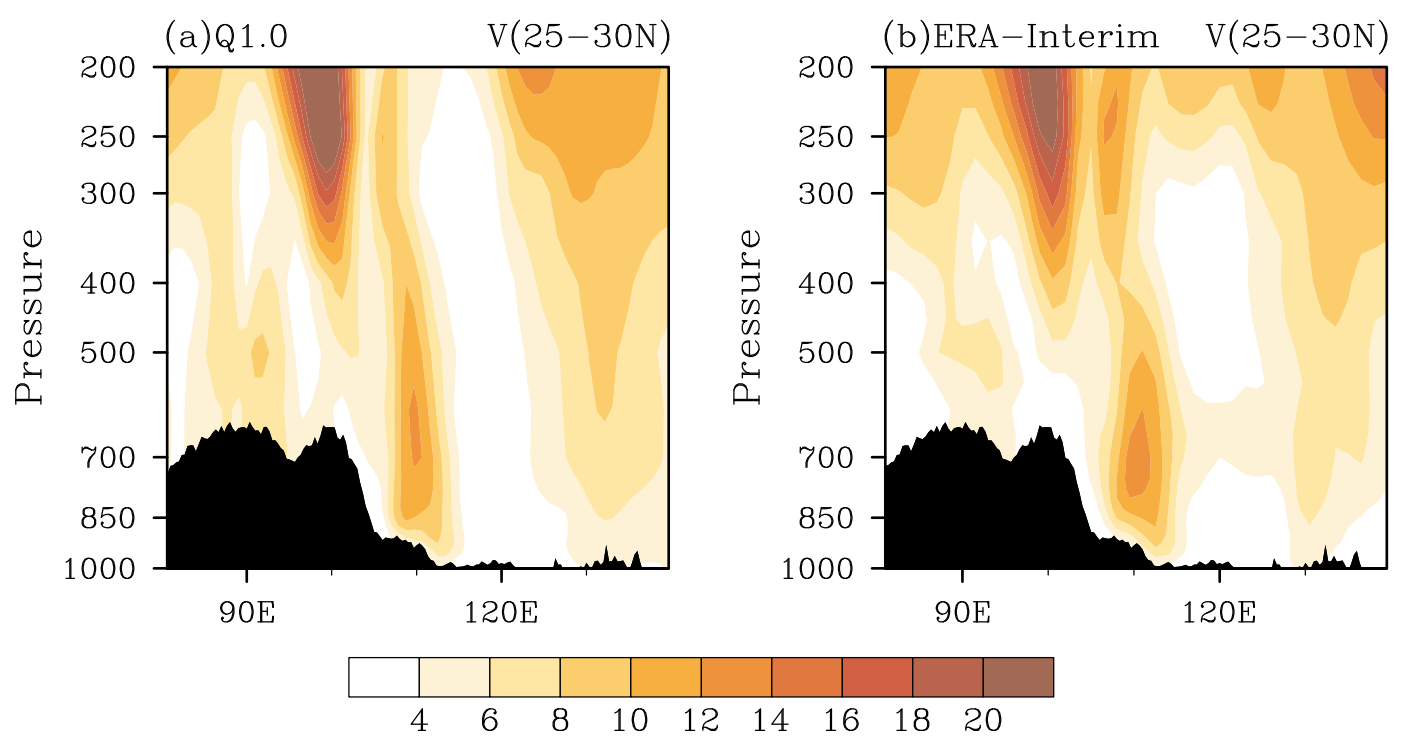

FIG. 3. Zonal sections of horizontal wind speeds $\left(\mathrm{m} \mathrm{s}^{-1}\right.$ ) averaged from $25^{\circ}$ to $30^{\circ} \mathrm{N}$ on $29 \mathrm{Jul} 2007$ for (a) Q1.0 and (b) ERA-Interim.

increased humidity is confined below $650 \mathrm{hPa}$ at the first forecast hour (Fig. 5b). Later in the development, the lower-tropospheric humidity anomaly at the LLJ inflow area quickly expands upward and northward, indicating ascending motion and deep convective activity particularly over southern land areas (see section 4a for a discussion of the implications), and moisture transport by the LLJ. At the 12th forecast hour-that is, 1200 UTC 28 July - the humidity anomaly has reached $300 \mathrm{hPa}$ in southern regions (Fig. 5c), but north of $30^{\circ} \mathrm{N}$ it is confined to the lower troposphere. At 1200 UTC 30 July, the heavy rainfall day in north China, the increased humidity has reached $40^{\circ} \mathrm{N}$ and a clear signature of deep convection can be observed in northern parts of the domain (Fig. $5 \mathrm{~g}$ ). Thus, the increased humidity at the LLJ inflow region is efficiently transported northward, accumulates over north China, and promotes the formation of deep convection and heavy precipitation after 2 days into the hindcast simulation.

\section{a. Large-scale response}

On the second day after initialization-that is, on 29 July 2007-the LLJ over southern China is less pronounced in Q1.5 than in Q1.0 (Figs. 6a,b). In Q1.5 the $850-\mathrm{hPa}$ southerlies near $110^{\circ} \mathrm{E}$ are weaker and the areas meeting the LLJ definition almost disappear (Fig. 6b). Since the LLJ is geostrophic to first order, the weakening of the LLJ is related to changes in pressure gradients. The differences in 850-hPa geopotential height reveal a low pressure anomaly over southeastern China (Fig. 6d). Considering the geopotential height pattern in Q1.0 (Fig. 6c), this lower-tropospheric low pressure anomaly weakens the east-west pressure gradients. As a result, the geostrophic southwesterlies to the west of the subtropical high decrease and so does the LLJ.

A zonal section of divergence differences averaged from $20^{\circ}$ to $30^{\circ} \mathrm{N}$ illustrates the vertical dynamic structure of the lower-tropospheric low pressure anomaly (Fig. 6e). There is strong divergence in the upper troposphere between $110^{\circ}$ and $120^{\circ} \mathrm{E}$ in Q1.5. The strong upper-tropospheric divergence induces a low pressure anomaly below and lower-tropospheric convergence. The zonal section of temperature differences over the same region shows that the upper-tropospheric air temperature is distinctly increased between $110^{\circ}$ and $120^{\circ} \mathrm{E}$ in Q1.5 (Fig. 6f), with maximum amplitude of more than $3 \mathrm{~K}$. Thus, a mid- and upper-tropospheric heating anomaly in Q1.5 is responsible for the lowertropospheric low pressure anomaly over southeastern China and the consequent weakening of the LLJ. The LLJ plays an important role in promoting precipitation, as illustrated by the notable precipitation along the LLJ in Q1.0 (Fig. 6g). However, although Q1.5 presents a weaker LLJ compared to Q1.0, the precipitation obviously increases over north China (Fig. 6h), suggesting that the increased humidity might surpass the decreased LLJ in influencing precipitation. The related dynamic processes will be discussed in detail later in section 5 .

To identify the source of the mid- and uppertropospheric heating anomaly in Q1.5, temperature tendencies due to various processes were analyzed. Figure 7 shows the differences of temperature tendencies due to radiative heating and condensational heating associated with cloud and convective precipitation 

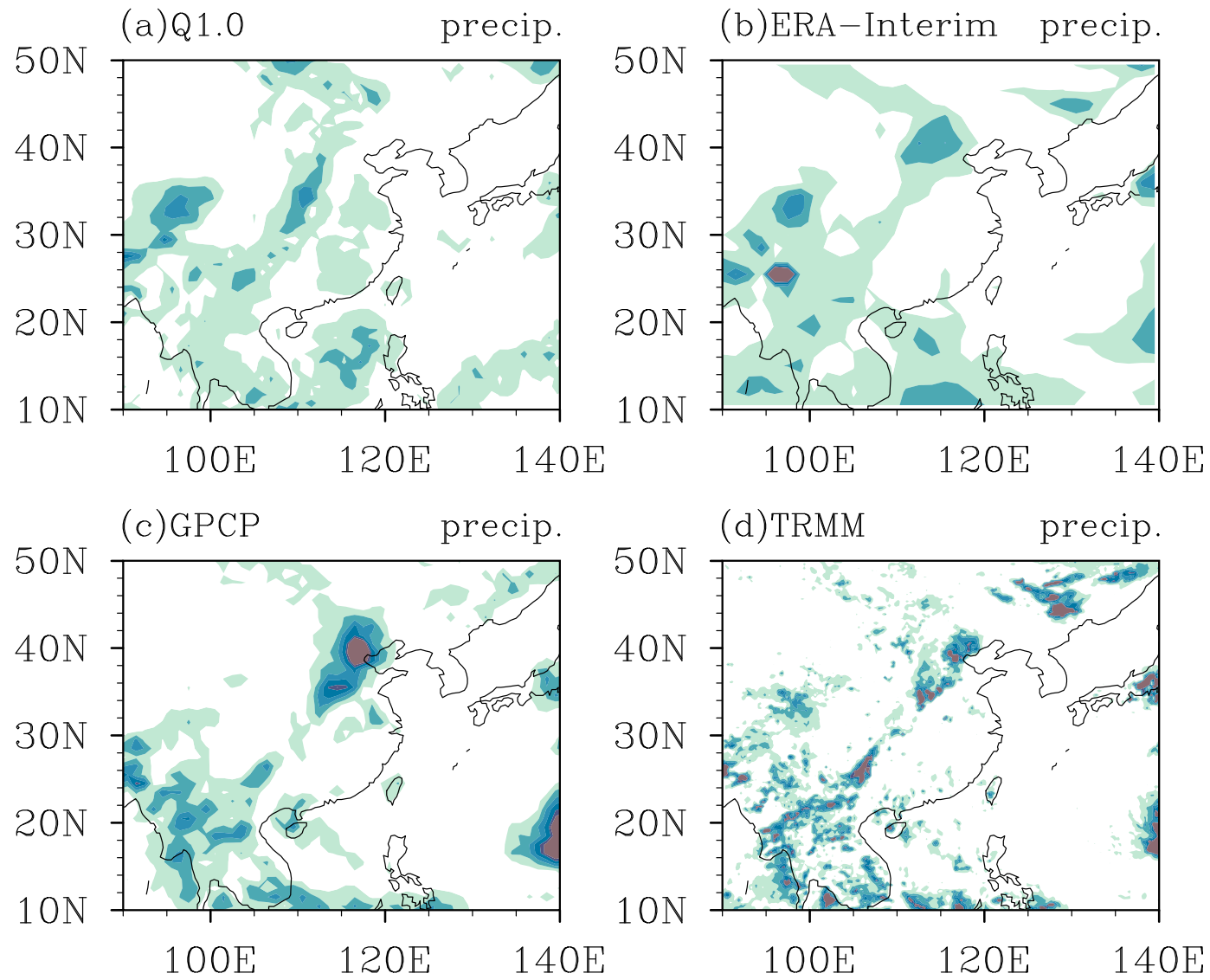

(d)TRMM precip.
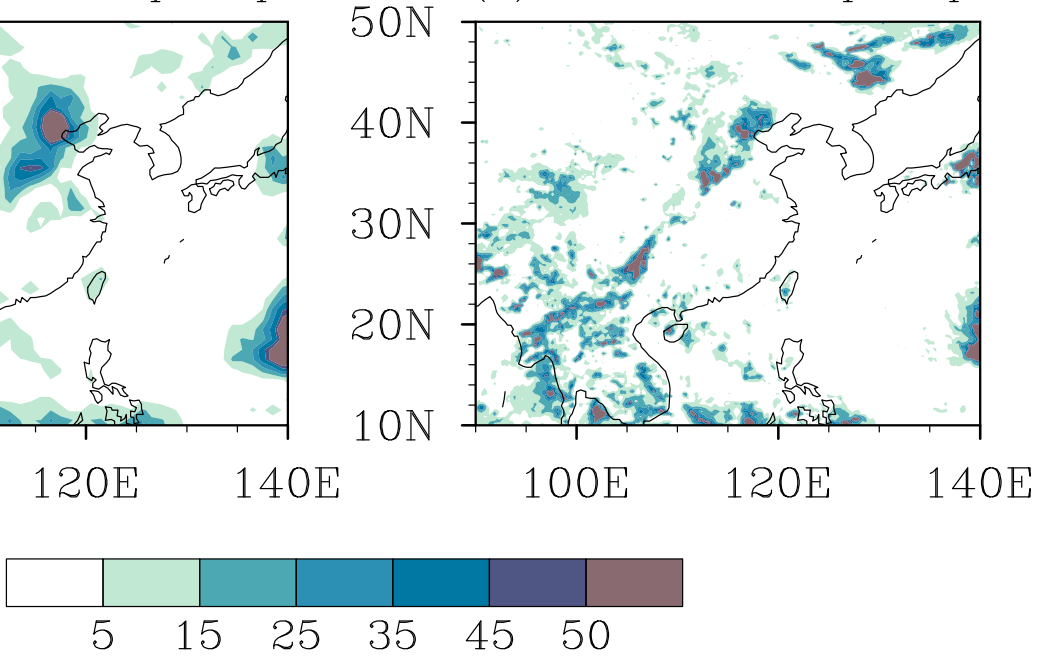

FIG. 4. Daily precipitation $\left(\mathrm{mm} \mathrm{day}^{-1}\right.$ ) on $30 \mathrm{Jul} 2007$ for (a) Q1.0, (b) ERA-Interim, (c) GPCP, and (d) TRMM.

formation. The contribution from radiative heating is modest, with maximum amplitude of about $1 \mathrm{~K}$ day $^{-1}$ in the middle troposphere, turning into a cooling effect in the upper troposphere between $110^{\circ}$ and $120^{\circ} \mathrm{E}$ (Fig. 7a). The radiative effects are associated with increased moisture content and cloud cover in the middle troposphere, and associated absorption of longwave radiation and increased cloud-top radiative cooling above. In contrast, the contribution from condensational heating is much larger, with maximum amplitude of more than $8 \mathrm{~K} \mathrm{day}^{-1}$ in the middle troposphere between $110^{\circ}$ and $120^{\circ} \mathrm{E}$ (Fig. $7 \mathrm{~b}$ ). The condensational heating can be attributed to deep convective activity associated with the prominent precipitation over southeastern China as indicated by Fig. 6h. Thus, the mid- and uppertropospheric heat source in Q1.5 stems mainly from condensational heating associated with deep convection. The condensational heating is partly advected upward, as can be deduced from the upper-tropospheric positive temperature anomaly center shown in Fig. $6 \mathrm{f}$. At lower latitudes, the lower-tropospheric low pressure anomaly is displaced somewhat to the west of the heat source, in agreement with the subtropical response to a heating anomaly as discussed in Hoskins and Karoly (1981) based on linear quasigeostrophic theory, as well as the Gill model of localized tropical heating (Gill 1980).

In summary, the increased humidity in the lower troposphere fuels deep convection in southern parts of the EASM region, giving rise to condensational heat release. The subsequent mid- and upper-tropospheric temperature increase causes divergence aloft and convergence and low pressure anomalies at lower levels. The near-surface low pressure anomaly in turn decreases east-west pressure gradients at lower levels of the atmosphere and results in a weakening of the southwesterly flow and the LLJ. This decrease in the strength of the low-level flow opposes the generally 

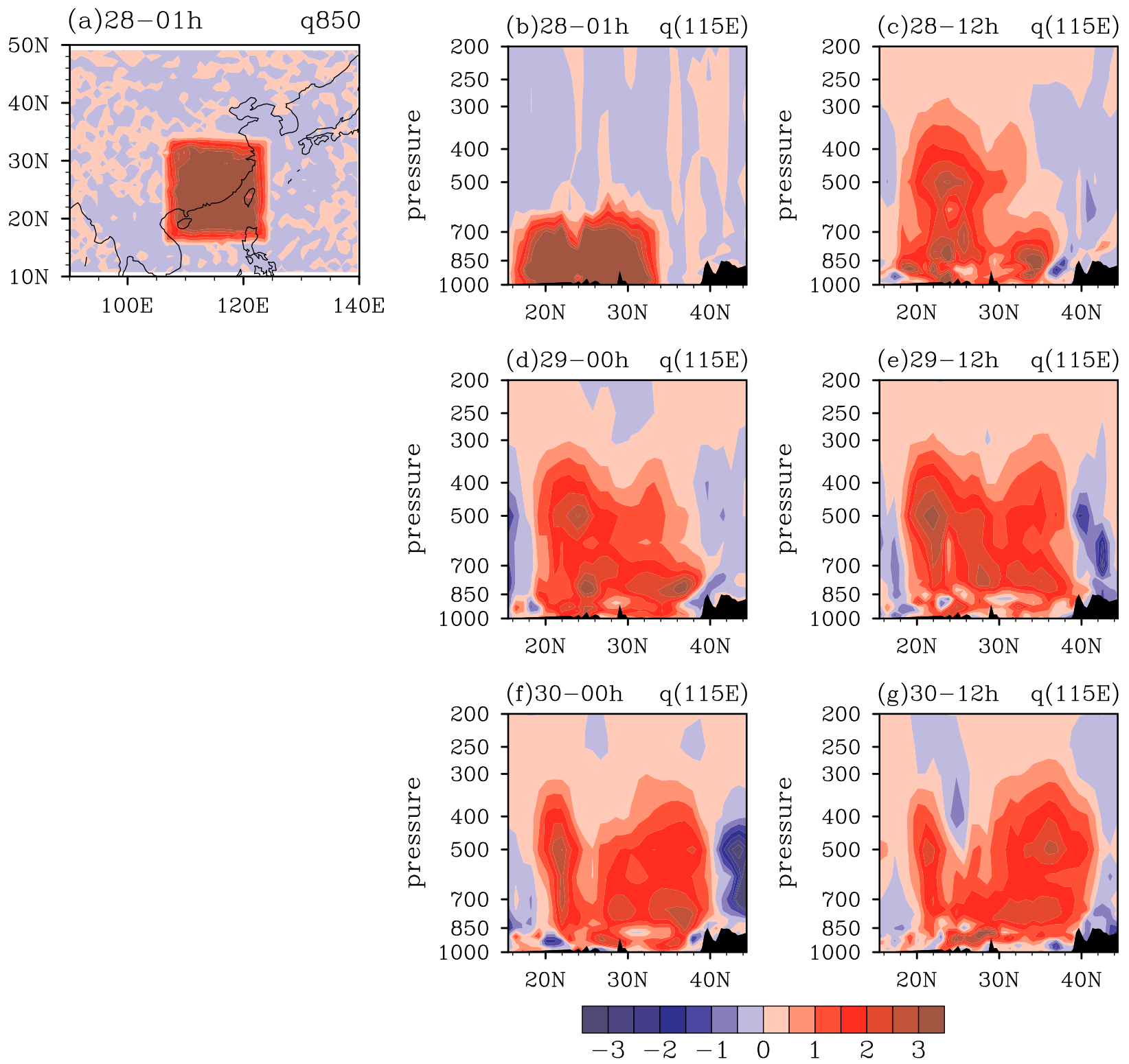

FIG. 5. Differences of specific humidity $\left(\mathrm{g} \mathrm{kg}^{-1}\right)$ between the sensitivity experiments Q1.5 and Q1.0 (Q1.5 - Q1.0): (a) the 850-hPa specific humidity at the first forecast hour, that is, $0100 \mathrm{UTC} 28 \mathrm{Jul}$; (b)-(g) its evolution in a meridional section along $115^{\circ} \mathrm{E}$ from 0100 UTC 28 Jul to 1200 UTC 30 Jul 2007.

increased south-north moisture transport due to increased atmospheric humidity content in Q1.5.

\section{b. Impact on diurnal variation}

Figure 8 shows the diurnal veering of the $850-\mathrm{hPa}$ perturbation wind vectors at 3-hourly intervals over the areas where the maximum LLJ winds occur. The daily mean wind vector over each grid point was thereby removed. In Q1.0 the perturbation wind exhibits an obvious clockwise rotation over time (Fig. 8a). During midnight to early morning [from 2300 to 0500 Beijing local standard time (LST)], there are clear southerly components in the perturbation wind, and the southerly amplitudes are largest at 0200 LST. During the daytime (from 0800 to 1700 LST), obvious northerly components occur in the perturbation wind, and the northerly amplitudes are largest at 1100 LST. The southerly perturbations enhance the LLJ while northerly perturbations reduce it, resulting in a stronger nocturnal LLJ and a weaker daytime LLJ. In Q1.5 the perturbation wind also exhibits a clear clockwise rotation over time with larger amplitude (Fig. 8b). Both the nocturnal southerly 

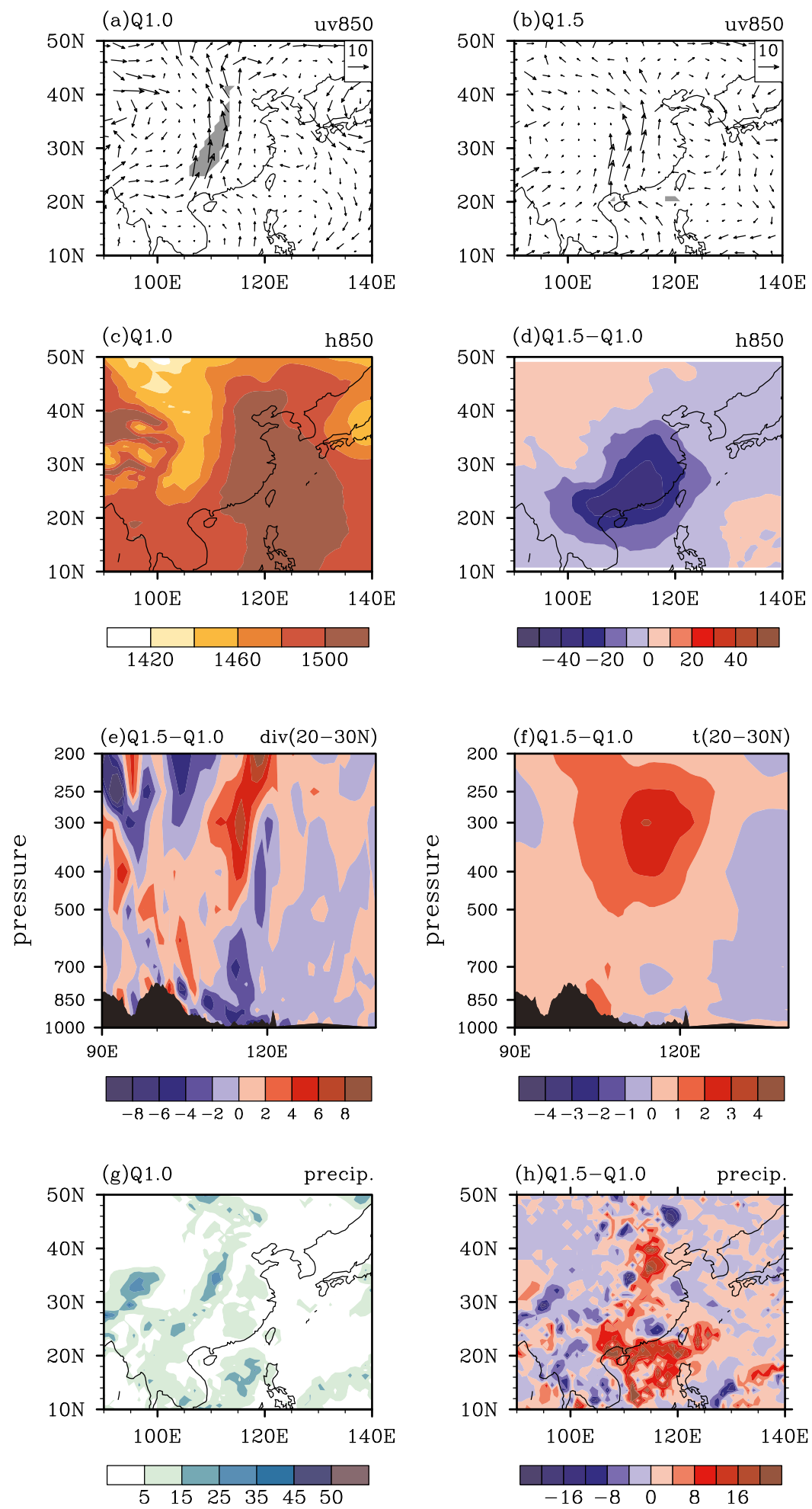

FIG. 6. The 850-hPa winds ( $\mathrm{m} \mathrm{s}^{-1}$ ) for (a) Q1.0 and (b) Q1.5 (shading denotes the areas meeting the definition of LLJ); 850-hPa geopotential height (gpm) for (c) Q1.0 and (d) Q1.5 - Q1.0; zonal sections of (e) divergence $\left(10^{-6} \mathrm{~s}^{-1}\right)$ and (f) air temperature (K) averaged from $20^{\circ}$ to $30^{\circ} \mathrm{N}$ for Q1.5 - Q1.0 on $29 \mathrm{Jul} 2007$; and precipitation $\left(\mathrm{mm} \mathrm{day}^{-1}\right.$ ) for (g) Q1.0 and (h) Q1.5 - Q1.0 on $30 \mathrm{Jul} 2007$. 

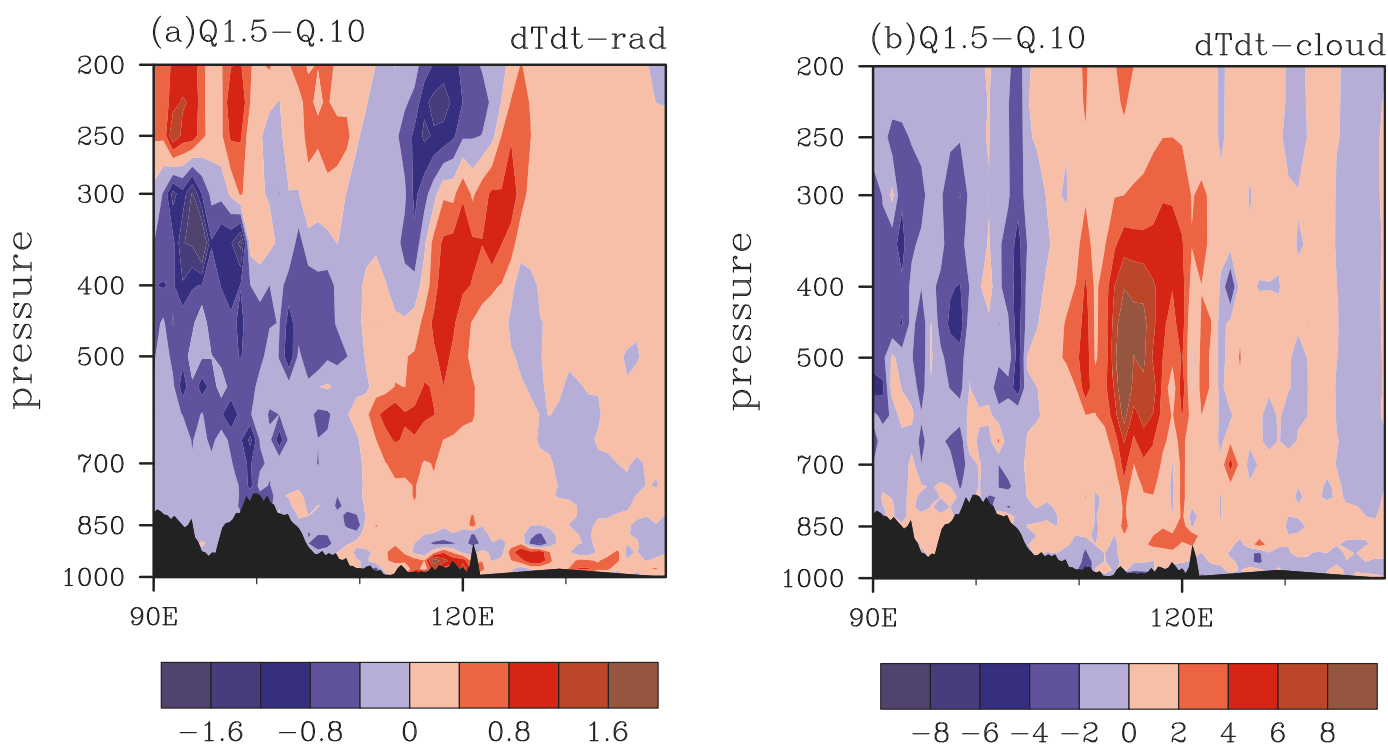

FIG. 7. Zonal sections of air temperature tendencies $\left(\mathrm{K} \mathrm{day}^{-1}\right)$ caused by (a) radiative heating and (b) condensation heating averaged from $20^{\circ}$ to $30^{\circ} \mathrm{N}$ for Q1.5 - Q1.0 on $29 \mathrm{Jul} 2007$.

perturbation wind and the daytime northerly perturbation wind are stronger in Q1.5, such that the LLJ shows a larger diurnal variation.

The larger diurnal variation of the LLJ in Q1.5 is mainly due to the stronger day-and-night thermal differences over the sloping terrain and consequently generated baroclinicity (Bleeker and Andre 1951; Holton 1967; Jiang et al. 2007). During daytime, the air near the mountain surface is heated faster because of the elevated heat effect. This leads to upslope winds that gradually veer clockwise under the influence of the Coriolis force, and finally exhibit a southerly component after several hours (during nighttime). The southerly component strengthens the original southwesterlies that result in a stronger nocturnal LLJ. The conditions are reversed during nighttime. There radiative cooling of air leads to gravity drainage along the mountain slope. Positive pressure anomalies build up first at the foot of the mountain range, which eventually push the air into the plains and give rise to convergence. Consequently, the downslope winds on the eastern slope veer clockwise and form a northerly component during daytime and weaken the LLJ.

Figure 9 displays the diurnal cycle of surface temperature and total heat flux (positive denotes downward flux) over the eastern slope of the Tibetan Plateau, averaged from $25^{\circ}$ to $30^{\circ} \mathrm{N}$ along $104^{\circ} \mathrm{E}$ (see the topography in Fig. 3). The diurnal cycle in surface temperature in Q1.5 is larger than in Q1.0: On 29 July the maximum temperature in the afternoon for Q1.5 is about $1.5 \mathrm{~K}$ higher, while the minimum temperature is only $0.5 \mathrm{~K}$ higher in the following early morning. The evolution of surface temperature can be explained by the diurnal cycle of the total heat flux at the surface (Fig. 9b). Here the total heat flux is the sum of the surface net shortwave radiative flux, the net longwave radiative flux, and sensible and latent heat fluxes. The diurnal cycle of the total heat flux for Q1.5 is larger than for Q1.0. In Q1.5 the maximum downward flux during the daytime on 29 July is about $20 \mathrm{~W} \mathrm{~m}^{-2}$ larger, while the upward flux differs little during nighttime. The larger diurnal cycle of total heat flux and the consequent larger diurnal cycle of surface temperature in Q1.5 is mostly due to less cloud cover over the mountain range (not shown). As illustrated in Fig. 6e, there are stronger upper-tropospheric convergence and lower-tropospheric divergence over the mountain in Q1.5, which leads to stronger descending motion, drier air conditions, and thus less cloud cover.

\section{Impact of moisture on rainfall}

The LLJ plays an important role in the occurrence of precipitation through moisture transport and convergence. The previous section shows that in Q1.5 the atmospheric moisture content in the LLJ inflow region is increased, but the LLJ becomes weaker. How do the two effects interact with each other and impact precipitation formation in the LLJ outflow region? To investigate this question and the associated dynamic processes, moisture and moist static energy budget analyses are conducted (Chen and Bordoni 2014). 
(a) Q1.0 uv850

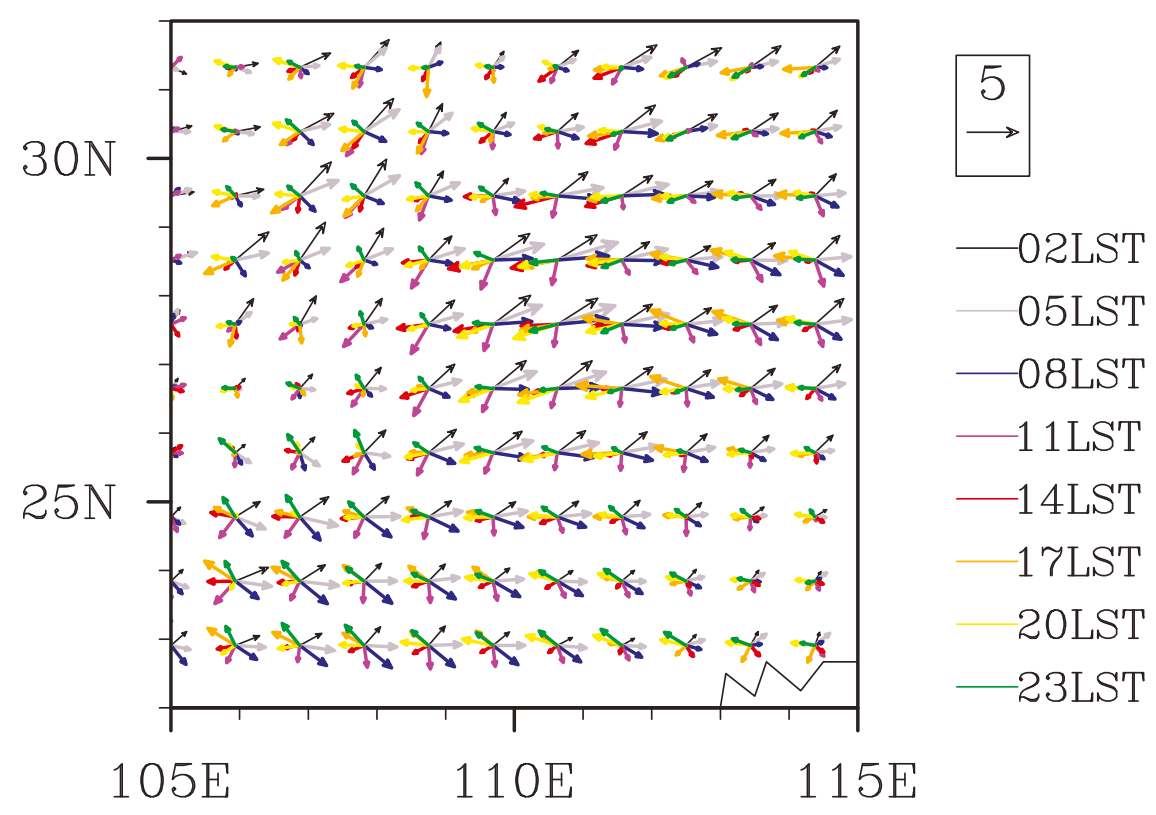

(b)Q1.5 uv850

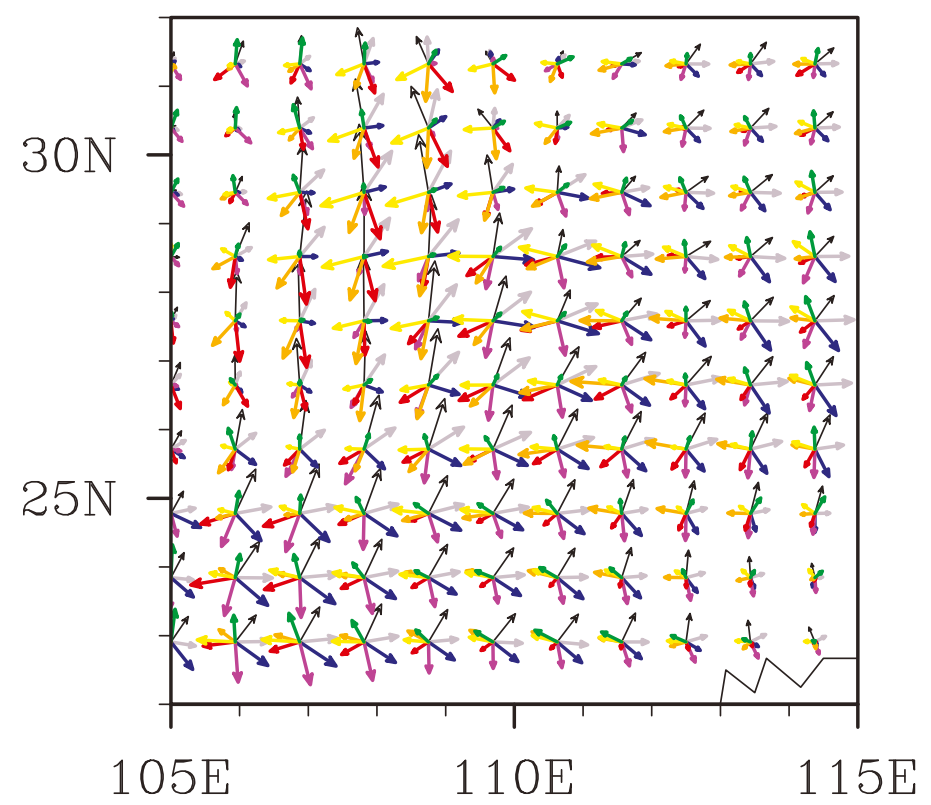

FIG. 8. Diurnal veering of 850-hPa perturbation wind vectors $\left(\mathrm{m} \mathrm{s}^{-1}\right)$ at 3-hourly intervals on $29 \mathrm{Jul} 2007$ for (a) Q1.0 and (b) Q1.5. The daily mean wind vector over each grid point is removed to get the perturbation wind.

The heavy precipitation in the LLJ outflow region over north China occurred on 30 July, so the analysis focuses on $30 \mathrm{July}$, that is, the third forecast day in the simulation. Daily mean is applied to all the equations in this section, calculated from the hourly output data. All 95 model hybrid levels comprising troposphere and stratosphere are included for vertical integrals. 


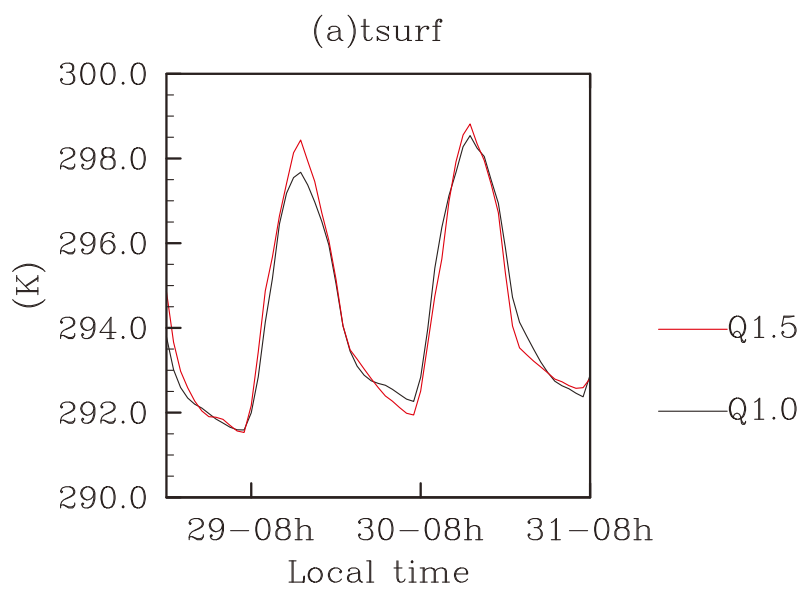

(b)heat flux

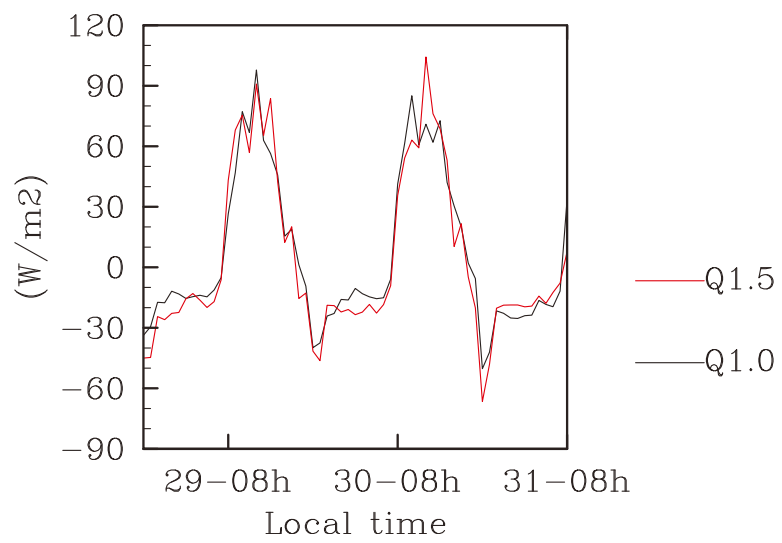

FIG. 9. Evolution of (a) surface temperature (K) and (b) total heat flux (positive denotes downward flux; $\mathrm{W} \mathrm{m}^{-2}$ ) from $0000 \mathrm{LST}$ 29 Jul to 0800 LST $31 \mathrm{Jul} 2007$ for Q1.0 (black lines) and Q1.5 (red lines) averaged between $25^{\circ}$ and $30^{\circ} \mathrm{N}$ along $104^{\circ} \mathrm{E}$ over the eastern slope of the Tibetan Plateau. The total heat flux is the sum of surface net shortwave, net longwave, and sensible and latent heat fluxes. The topography is shown in Fig. 3.

\section{a. Moisture and energy budget analysis}

\section{1) Moisture Budget}

To identify the most relevant processes that contribute to precipitation formation, we compute the different terms in the moisture budget equation:

$$
\left\langle\overline{\frac{\partial q}{\partial t}}\right\rangle+\langle\overline{\nabla \cdot(\mathbf{v} q)}\rangle+\left\langle\overline{\frac{\partial}{\partial p}(\omega q)}\right\rangle=-\bar{P}+\bar{E}
$$

where $q$ is specific humidity, $P$ is precipitation, and $E$ is evaporation; $\overline{(\cdot)}$ means temporal mean; and $\langle\cdot\rangle$ indicates a vertical mass integral, that is, $\int(\cdot) d p / g$.

Figure 10 shows the differences between Q1.5 and Q1.0 for each term in the moisture budget equation. The sign of each term is flipped, for convenience of discussing the change of precipitation. Q1.5 features more precipitation over eastern China (Fig. 10a). Precipitation is enhanced particularly over the areas along the LLJ, and the center of the maximum increase over land is located in the LLJ outflow region over north China. The evaporation term $-\bar{E}$ and the vertical advection term $-\langle\overline{\partial \omega q / \partial p}\rangle$ change little over north China in Q1.5 (Figs. 10b,e). The heavier precipitation in Q1.5 can mostly be attributed to the horizontal moisture flux convergence $-\langle\overline{\nabla \cdot(\mathbf{v} q)}\rangle$ (Fig. 10d). In Q1.5 there is more moisture flux convergence over north China, contributing to about $20 \mathrm{~mm} \mathrm{day}^{-1}$ more precipitation.

The change in moisture flux convergence $-\langle\overline{\delta[\nabla \cdot(\mathbf{v} q)]}\rangle$ can approximately be decomposed into a contribution due to changes in humidity $-\langle\overline{\nabla \cdot(\mathbf{v} \delta q)}\rangle$ and a contribution due to changes in the circulation $-\langle\overline{\nabla \cdot(\delta \mathbf{v} q)}\rangle$. Figures 11a and $11 \mathrm{~b}$ show the respective contributions of the two terms. The change associated with the wind shows convergence mostly along the LLJ (Fig. 11b), contributing only modestly to the stronger moisture flux convergence over north China in Q1.5. In contrast, the signal associated with humidity changes exhibits strong localized convergence in the outflow region of the LLJ over north China (Fig. 11a), thus explaining an important part of the stronger moisture flux convergence in Q1.5 (Fig. 10d).

Therefore, the heavier precipitation over north China primarily arises from the changed abundance of moisture at the exit region accumulated by the LLJ. A further decomposition of $-\langle\overline{\nabla \cdot(\mathbf{v} \delta q)}\rangle$ into $-\langle\overline{\mathbf{v} \nabla(\delta q)}\rangle$ and $-\langle\overline{\delta q \nabla \mathbf{v}}\rangle$ indicates that the gradient of $\delta q$ plays a critical role over north China (Figs. 11c,d). Thus, over north China, which is located at the northern margin of the East Asian summer monsoon, the horizontal gradient (mostly the meridional gradient) of humidity is crucial for the convergence of moisture.

\section{2) Moist Static Energy Balance}

The moist static energy (MSE) budget takes the comprehensive effects of temperature, humidity, and diabatic processes into consideration and is therefore well suited for the analysis of tropical-subtropical circulations (Chen and Bordoni 2014). The MSE balance equation is defined as follows:

$$
\left\langle\frac{\partial E}{\partial t}\right\rangle=\overline{F^{\text {net }}}-\langle\overline{\mathbf{v} \cdot \nabla E}\rangle-\left\langle\overline{\omega \frac{\partial h}{\partial p}}\right\rangle .
$$

Here $E=c_{p} T+L_{v} q$ is the atmospheric moist enthalpy and $h=c_{p} T+g z+L_{v} q$ is the moist static energy. The term $F^{\text {net }}$ denotes the net energy flux into the atmosphere: 

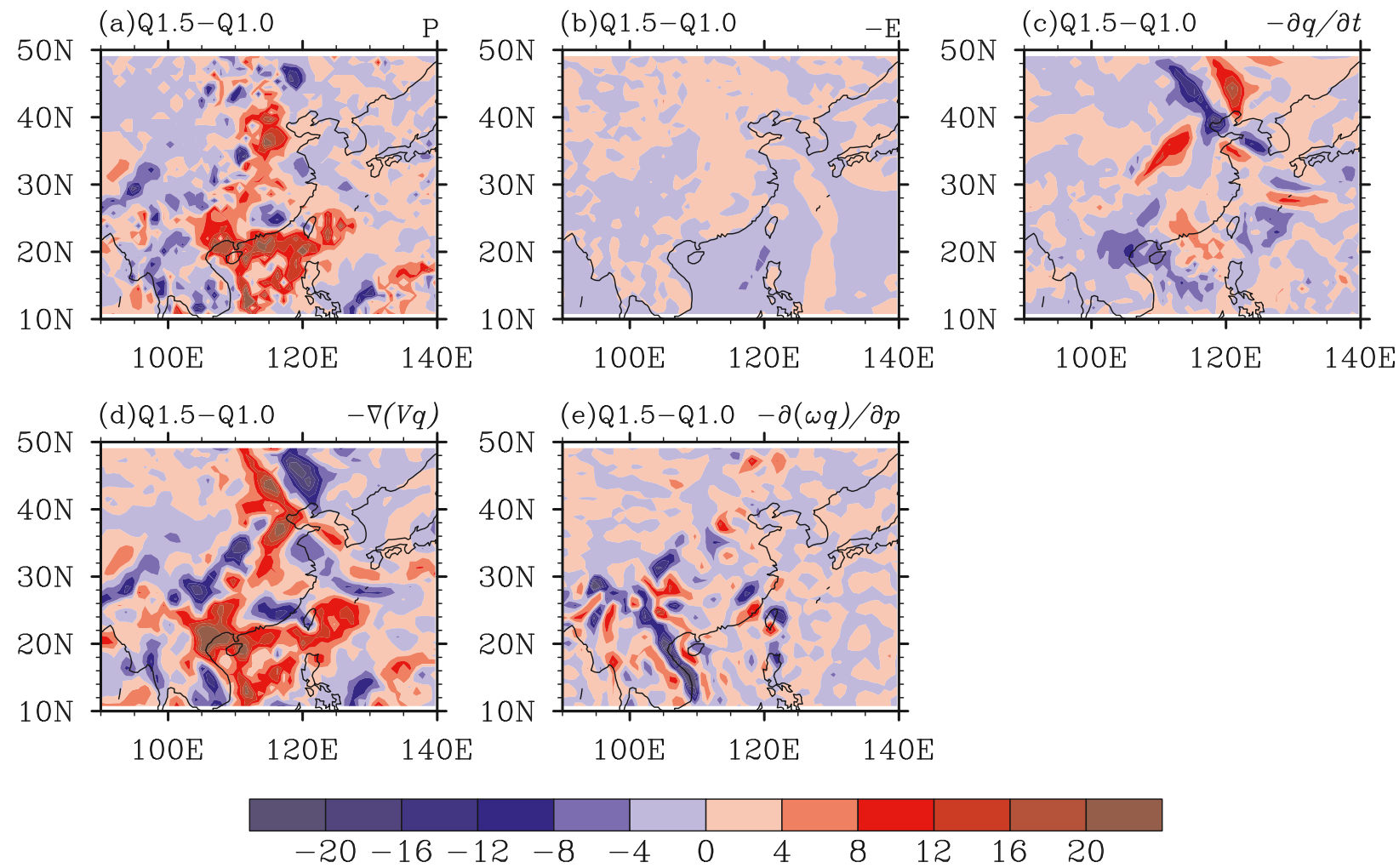

FIG. 10. Differences of each term in the moisture budget equation for Q1.5 - Q1.0 on 30 Jul 2007: (a) $\bar{P}$, (b) $-\bar{E}$, (c) $\langle\overline{\partial q / \partial t}\rangle$, (d) $-\langle\bar{\nabla} \cdot(\mathbf{v} q)\rangle$, and $(\mathrm{e})-\langle\overline{\partial(\omega q) / \partial p}\rangle\left(\mathrm{mm} \mathrm{day}^{-1}\right)$.

$F^{\text {net }}=S_{t}^{\downarrow}-S_{t}^{\uparrow}-S_{s}^{\downarrow}+S_{s}^{\uparrow}-R_{t}^{\uparrow}+R_{s}^{\uparrow}-R_{s}^{\downarrow}+\mathrm{SH}+\mathrm{LH}$.

As discussed by Chen and Bordoni (2014), the vertical MSE advection term $-\langle\overline{\omega \partial h / \partial p}\rangle$ (Fig. 12d) is closely linked to precipitation $\bar{P}$ (Fig. 10a). There are negative changes in this term along the LLJ and a negative extreme is located over north China, corresponding to the center of precipitation increase. Therefore, the MSE balance equation helps to analyze the changes in precipitation from an energetic perspective. The change in the local storage of the atmospheric moist enthalpy $\langle\overline{\partial E / \partial t}\rangle$ (Fig. 12a) exhibits a pattern similar to the change in local storage of specific humidity $\langle\overline{\partial q / \partial t}\rangle$ (Fig. 10c). The differences of $F^{\text {net }}$ show no signal over north China, contributing little to the heavier precipitation (Fig. 12b). In contrast, the horizontal advection of moist enthalpy $\langle\overline{\mathbf{v} \cdot \nabla E}\rangle$ shows a great increase over north China (Fig. 12c), contributing most to the heavier precipitation through an enhanced import of energy from southern areas that may fuel convection. A further decomposition of $\langle\overline{\mathbf{v} \cdot \nabla E}\rangle$ into a component related to temperature $-\left\langle\overline{\mathbf{v} \cdot \nabla\left(c_{p} T\right)}\right\rangle$ and a component related to humidity $-\left\langle\overline{\mathbf{v} \cdot \nabla\left(L_{v} q\right)}\right\rangle$ demonstrates that both components increase over north China (not shown), indicating that the increased horizontal enthalpy advection is due to a combination of high temperature and high moisture associated with the air from the south.

\section{b. Nocturnal rainfall peak}

With the enhanced LLJ during nighttime, as discussed in section 5b, comes a nocturnal precipitation peak in the observations. Figure 13 shows the daytime and nighttime precipitation from TRMM, ERA-Interim, Q1.0, and Q1.5. Here, daytime precipitation is from 0000 to 1200 UTC 30 July - that is, from 0800 to 2000 LST - and nighttime precipitation is from 1200 UTC 30 July to 0000 UTC 31 July - that is, from 2000 LST 30 July to 0800 LST 31 July. In TRMM, precipitation occurs along the LLJ areas during daytime (Fig. 13a) and concentrates over north China during nighttime (Fig. 13b). The nocturnal precipitation over north China is very heavy, with an amplitude of more than $30 \mathrm{~mm}$, indicating a nocturnal maximum. ERA-Interim shows similar patterns as TRMM but with much smaller amplitudes (Figs. 13c,d). For example, the amplitude of nocturnal precipitation over north China is only $15 \mathrm{~mm}$, nearly half of that in TRMM. In Q1.0 the model captures most of the daytime precipitation along the LLJ (Fig. 13e) but fails to simulate the nocturnal precipitation peak: there is almost no nocturnal precipitation over north China (Fig. 13f). In 

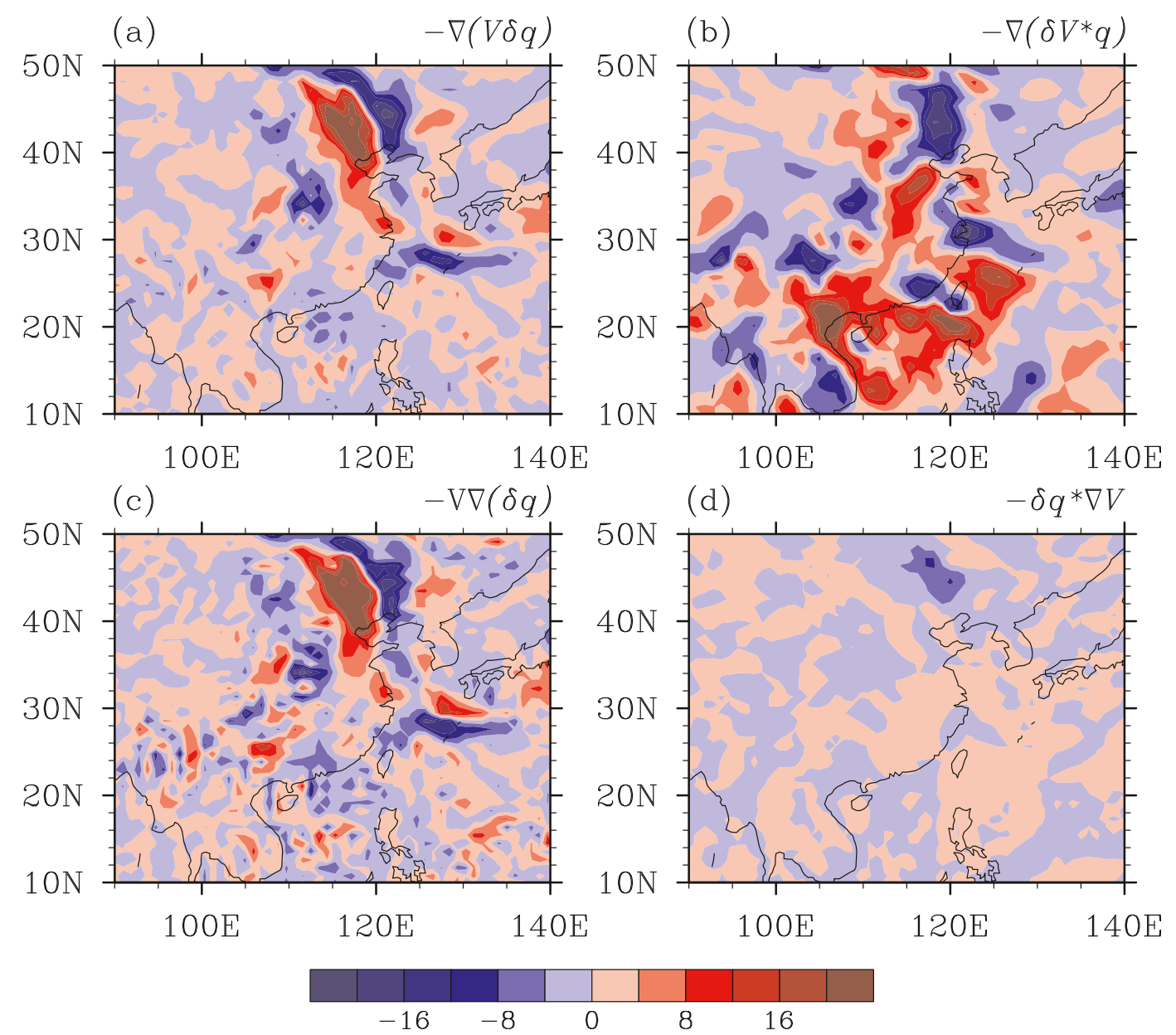

FIG. 11. Decomposition of the changes of horizontal moisture flux convergence $-\langle\overline{\delta[\nabla \cdot(\mathbf{v} q)]}\rangle$ into (a) $-\langle\overline{\nabla \cdot(\mathbf{v} \delta q)}\rangle$ and (b) $-\langle\overline{\boldsymbol{\nabla} \cdot(\delta \mathbf{v} q)}\rangle$, and the decomposition of $-\langle\overline{\boldsymbol{\nabla} \cdot(\mathbf{v} \delta q)}\rangle$ into (c) $-\langle\overline{\mathbf{v}(\delta q)}\rangle$ and (d) $-\langle\overline{\delta q \nabla \mathbf{v}}\rangle$ for the case on $30 \mathrm{Jul}$ $2007\left(\mathrm{~mm} \mathrm{day}^{-1}\right)$. Term $\delta(\cdot)$ denotes Q1.5 - Q1.0.

comparison, Q1.5 can reproduce both the daytime and nighttime precipitation patterns (Figs. 13g,h). The precipitation in Q1.5 is overall stronger than in Q1.0, and the nocturnal peak occurs over north China in Q1.5.

The missing of the nocturnal precipitation peak in Q1.0, and the analysis in previous sections, suggests a deficiency of the model in simulating the LLJ-related precipitation, which also occurs in other AGCMs (Jiang et al. 2007). The Q1.5 run reproduces the nocturnal precipitation in the LLJ outflow region distinctly better, providing an opportunity to explore the source of the model deficiency. We choose a box, $38^{\circ}-44^{\circ} \mathrm{N}, 112^{\circ}-$ $118^{\circ} \mathrm{E}$, that is located over the nocturnal heavy precipitation (as indicated by the dashed box in Fig. 13h) and analyze the box-mean nocturnal profiles of variables associated with precipitation processes. Figure 14 shows a comparison of profiles from ERA-Interim, Q1.0, and Q1.5. The vertical structures of specific humidity are quite similar in ERA-Interim and the model experiments: the humidity values in the boundary layer are in fact almost identical (Fig. 14a). Interestingly, both model experiments exhibit more humidity than ERAInterim, even Q1.0. And the vertical velocity profiles (Fig. 14d) indicate that the smaller humidity values in ERA-Interim are not a consequence of stronger deep convective activity. Thus, the abundance of specific humidity per se is not responsible for the absence of nocturnal precipitation in Q1.0.

The profiles of horizontal moisture flux divergence show discernible differences between reanalysis and experiments (Fig. 14b). ERA-Interim exhibits strong convergence in the boundary layer, with a modest secondary peak in convergence around the height of the LLJ around $750 \mathrm{hPa}$. In contrast, Q1.0 shows divergence below $800 \mathrm{hPa}$ and slight convergence in the middle troposphere. The lower-tropospheric divergence contributes to the weaker precipitation over north China in Q1.0 compared to ERA-Interim (Figs. 13f,d). Analyses 

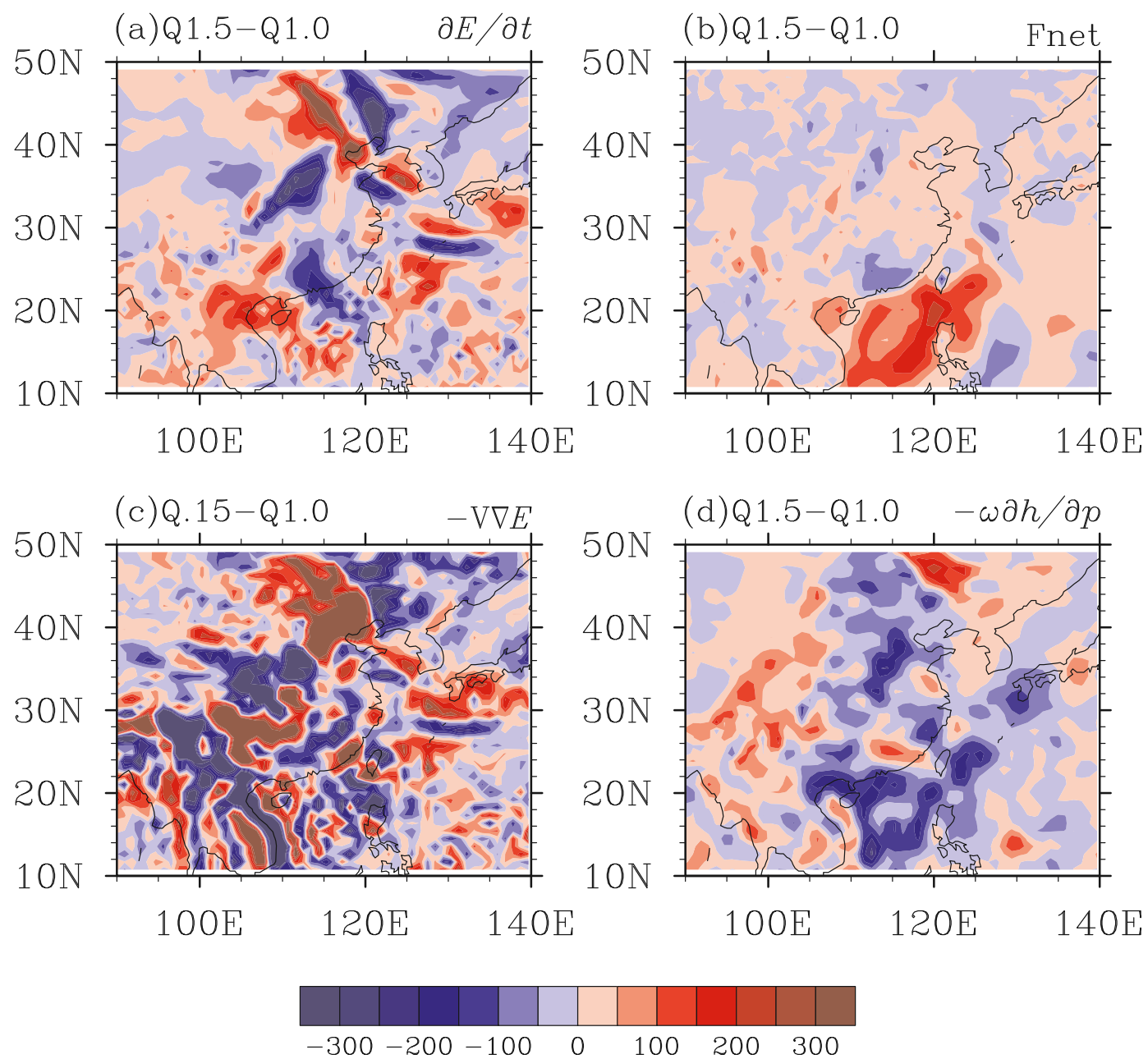

FIG. 12. Differences of each term in the MSE balance equation for Q1.5 - Q1.0 on $30 \mathrm{Jul} 2007$ : (a) $\langle\overline{\partial E / \partial t}\rangle$, (b) $\overline{F^{\text {net }}}$, (c) $-\langle\overline{\mathbf{v} \cdot \nabla E}\rangle$, and (d) $-\langle\overline{\omega \partial h / \partial p}\rangle\left(\mathrm{W} \mathrm{m}^{-2}\right)$.

of the moisture budget differences between Q1.0 and ERA-Interim indicate that the weaker precipitation over north China in Q1.0 is due to a stronger local storage of specific humidity and a weaker moisture flux convergence, and the weaker moisture flux convergence is mainly caused by a weaker convergence of horizontal winds associated with the LLJ at the jet outflow region (not shown). Compared to the other profiles, in Q1.5 the moisture flux convergence around the height of the LLJ is greatly enhanced, which favors nocturnal precipitation.

The MSE profile of ERA-Interim shows a distinctly unstable upper boundary layer and lower free troposphere, while Q1.0 and Q1.5 exhibit near-neutral profiles (Fig. 14c) at these levels. Thus, atmospheric stability and consequent convective inhibition cannot be the reason for the smaller convective activity in ERAInterim compared to Q1.5. The profiles of vertical wind just confirm the stronger deep convection and related precipitation in Q1.5 compared to both ERAInterim and Q1.0 (Fig. 14d). Therefore, taking into account the results of section $5 \mathrm{a}$, one can summarize that the LLJ plays a decisive role in triggering nighttime deep convection and associated rainfall. Thereby neither increased mechanical uplift nor the change in atmospheric stability caused by the LLJ are the main controlling factors of the enhanced nighttime rainfall in the Q1.5 experiment, but it is the change in the meridional moisture gradients and the related moisture convergence at the LLJ exit region that is decisive.

\section{Case on 21 July 2012}

Another case with heavy rainfall in the LLJ outflow region over north China on 21 July 2012 was also investigated, performing the same experiments and 
(a)TRMM

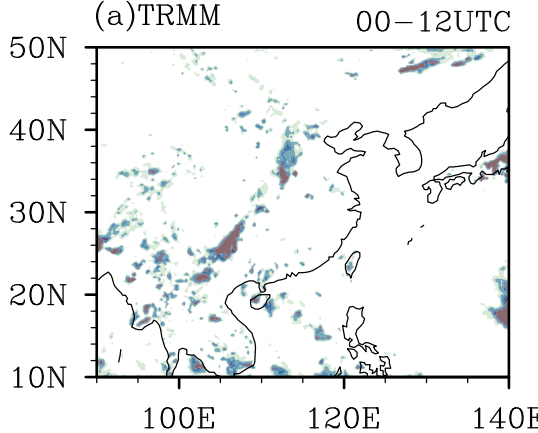

(c)ERA-Interim 00-12UTC

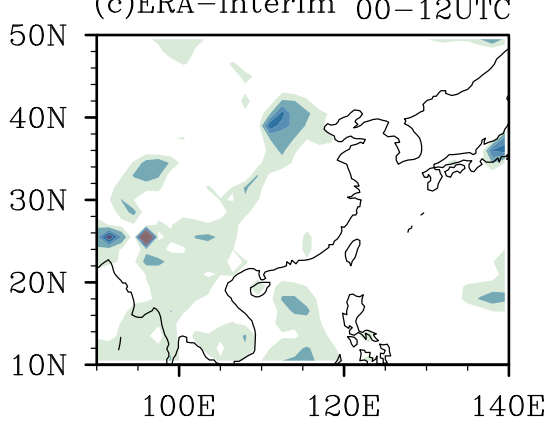

(e)Q1.0

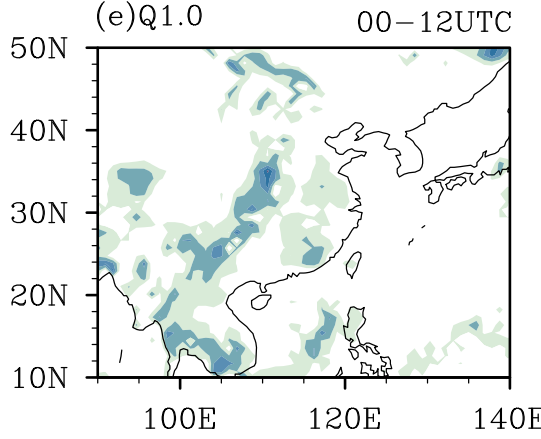

(g)Q1.5

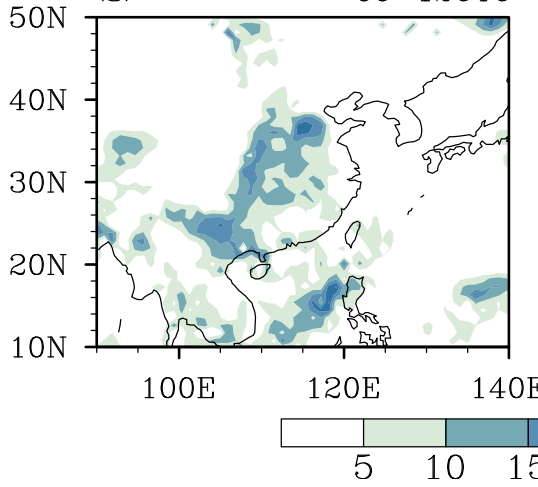

(b)TRMM

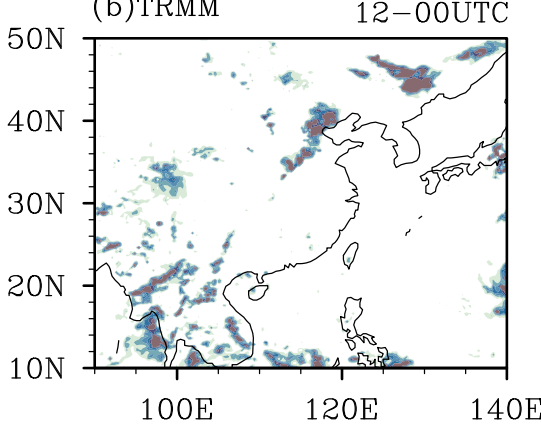

(d)ERA-Interim 12-00UTC
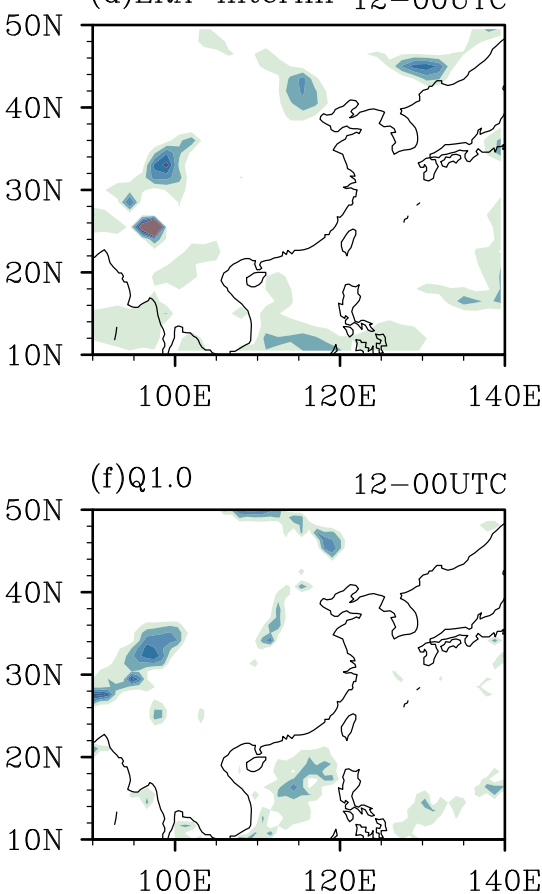

(h)Q1.5 12-00UTC

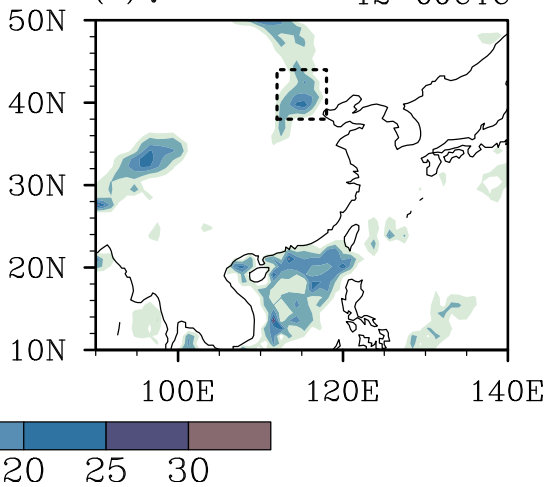

Fig. 13. (a),(c),(e),(g) Daytime (0000-1200 UTC 30 Jul 2007) and (b),(d),(f),(h) nighttime (1200 UTC 30 Jul-0000 UTC 31 Jul 2007) precipitation (mm) for (a),,(b)TRMM; (c),(d) ERAInterim; (e),(f) Q1.0; and (g),(h) Q1.5. The dashed box $\left(38^{\circ}-44^{\circ} \mathrm{N}, 112^{\circ}-118^{\circ} \mathrm{E}\right)$ in (h) is used for the average computation of profiles in the other panels. 
(a)

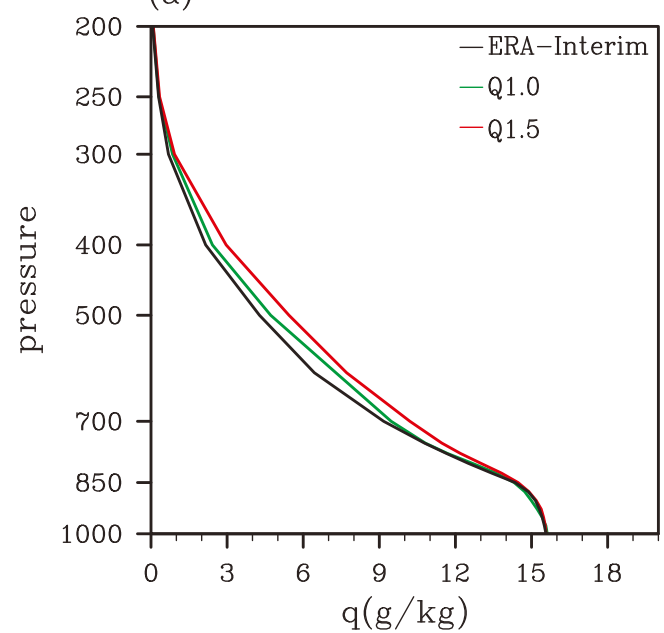

(c)

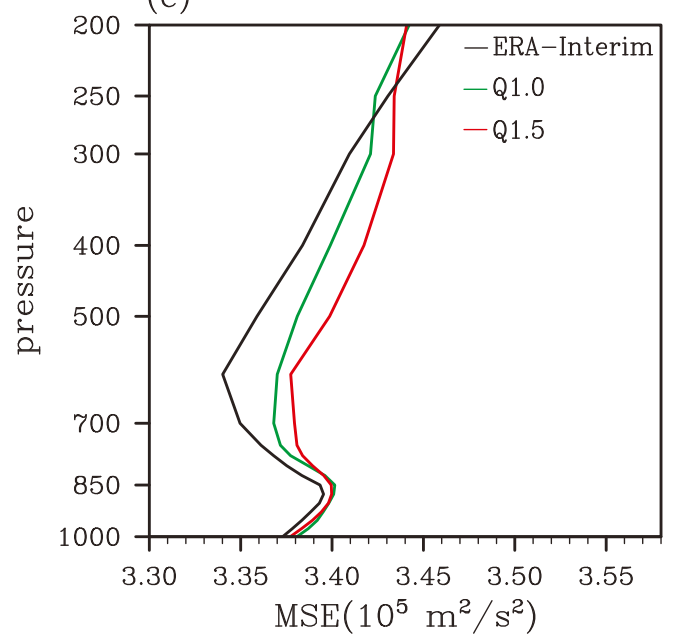

(b)

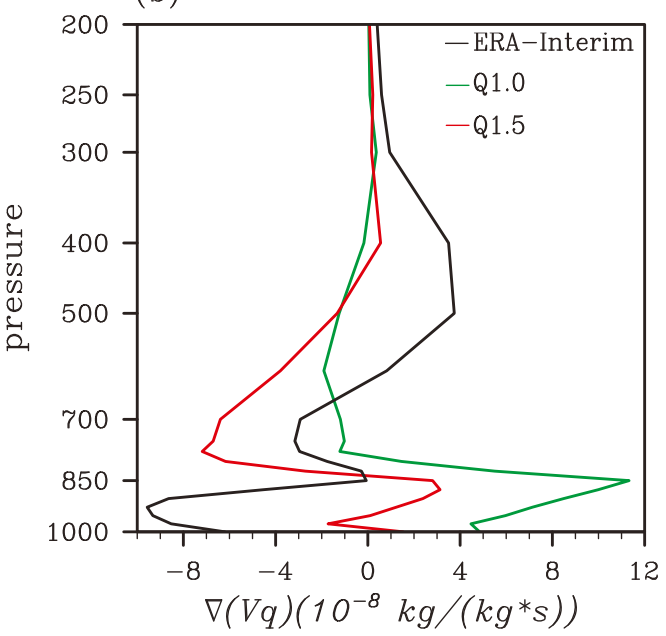

(d)

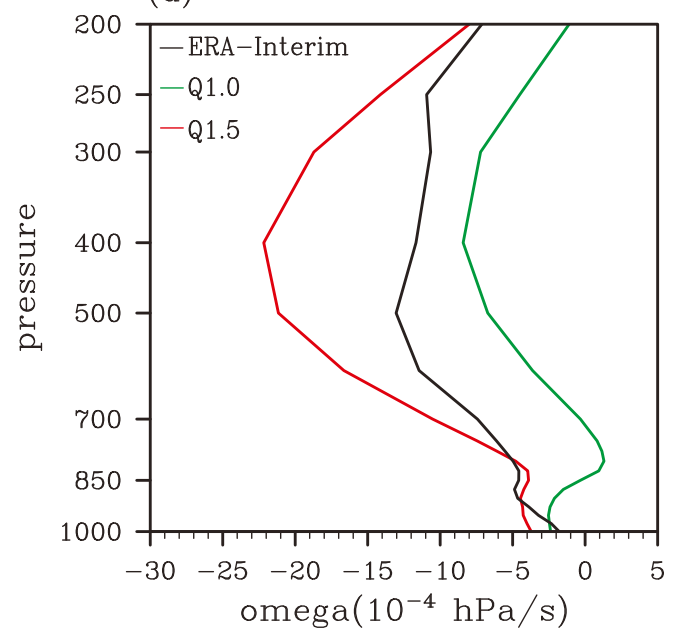

FIG. 14. Nocturnal profiles averaged from 1200 UTC 30 Jul to 0000 UTC 31 Jul 2007 over $38^{\circ}-44^{\circ} \mathrm{N}, 112^{\circ}-118^{\circ} \mathrm{E}$ (as indicated by the dashed box in Fig. 13h): (a) specific humidity $\left(\mathrm{g} \mathrm{kg}^{-1}\right)$, (b) horizontal moisture flux divergence $\left[10^{-8} \mathrm{~kg}(\mathrm{~kg} \mathrm{~s})^{-1}\right]$, (c) MSE $\left(10^{5} \mathrm{~m}^{2} \mathrm{~s}^{-2}\right)$, and (d) vertical velocity $\left(10^{-4} \mathrm{hPa} \mathrm{s}{ }^{-1}\right)$. The black lines denote ERA-Interim, green lines denote Q1.0, and red lines denote Q1.5.

analyses. The changes of the LLJ and large-scale circulation are consistent with the case on 30 July 2007: On the one hand, in Q1.5 the LLJ becomes weaker, which is due to increased upper-tropospheric condensational heating and the subsequent lower-tropospheric lower pressure over southeastern China (not shown). On the other hand, the diurnal variation of the LLJ gets stronger, resulting from a stronger diurnal cycle of heat fluxes over the sloping topography (not shown).

However, in this case the Q1.5 experiment shows less precipitation over north China compared to Q1.0 (Fig. 15a). An analysis of the moisture budget reveals that the decreased precipitation is mostly due to a weaker moisture flux convergence $-\langle\overline{\nabla \cdot(\mathbf{v} q)}\rangle$ over north China (Fig. 15d). A further decomposition of the change in moisture flux convergence $-\langle\overline{\delta[\nabla \cdot(\mathbf{v} q)]}\rangle$ into a change associated with humidity $-\langle\overline{\nabla \cdot(\mathbf{v} \delta q)\rangle}$ and a change associated with the wind $-\langle\overline{\nabla \cdot(\delta \mathbf{v} q)}\rangle$ indicates that the change of the wind field contributes foremost to the increased divergence over north China, while the change of humidity causes an increased convergence (Figs. 16a,b). Thus, the decreased precipitation over north China in this case is mainly due to less convergence of horizontal winds as a consequence of the weaker LLJ. This effect is different from the one in the previous case, in which the increased humidity dominated the response and led to more moisture flux convergence and subsequent heavier precipitation over north China. Therefore, one can conclude that an increase in atmospheric humidity content and the 

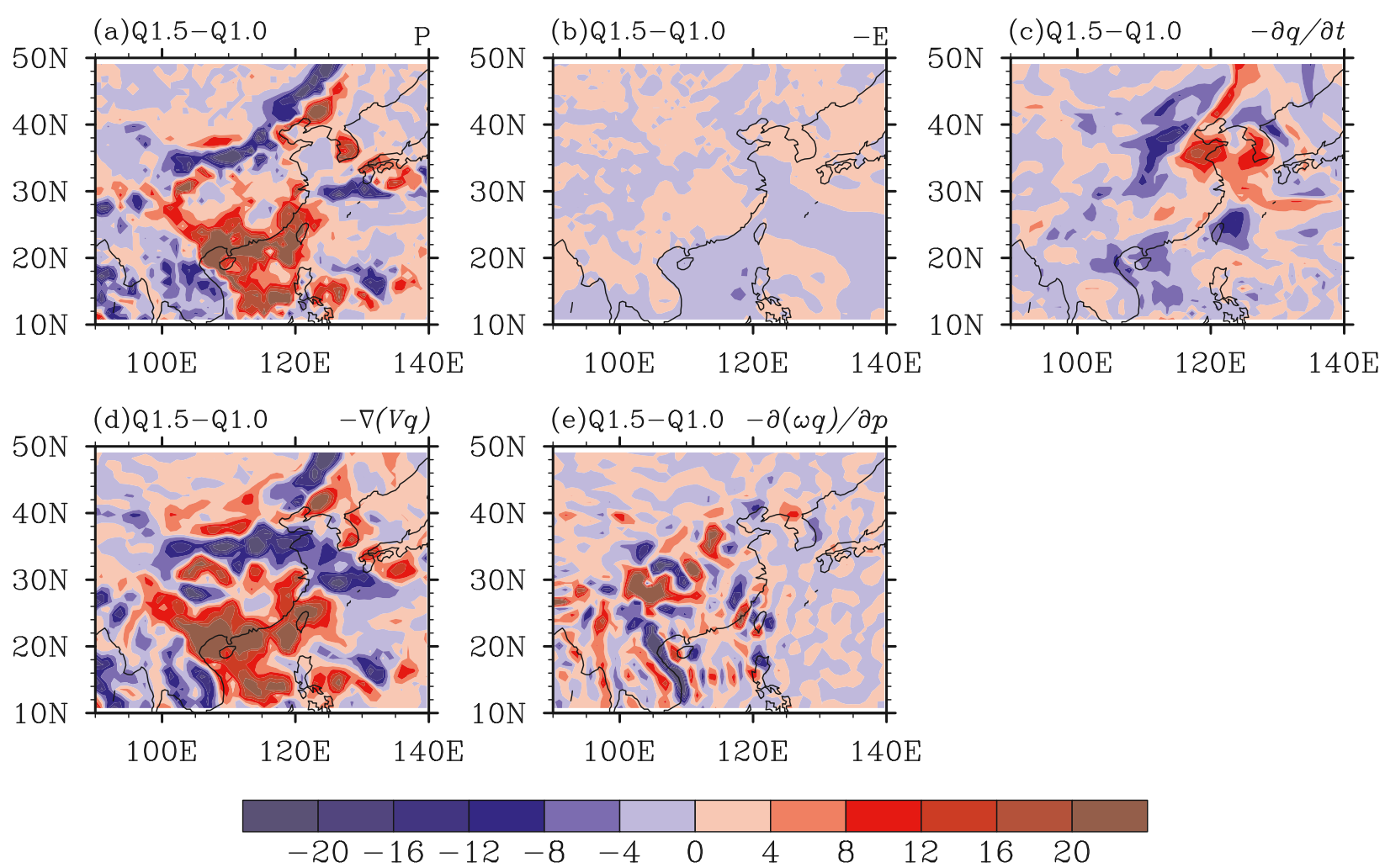

FIG. 15. As in Fig. 10, but for the case on 21 Jul 2012.

concurrent weakening of the LLJ represent competing effects that in combination determine the impact on precipitation in the LLJ outflow region. If the enhanced humidity dominates over the decreased strength of the LLJ, then there is stronger moisture flux convergence and more precipitation over north China, as in the case of 30 July 2007. Otherwise, if the decreased LLJ dominates over the increased humidity, then stronger moisture flux divergence and less precipitation is to be expected over north China, as in the case of 21 July 2012.

\section{Conclusions}

Using reanalysis data, rainfall observations, and sensitivity experiments with the global atmospheric general circulation model ECHAM6, the role of moisture in summertime LLJ and related precipitation formation in the outflow region is investigated over the East Asian monsoon region, focusing on two case studies. We propose a way of investigating the interaction between diabatic moist processes and the atmospheric circulation by means of changing initial conditions in hindcast experiments. The advantage of this approach is that, due to the rather short simulation time, numerical experiments at a wide range of resolutions can be performed, including, in principle, runs at large-eddy-resolving scales.
Moreover, observations can be taken advantage of, in contrast to more idealized experimental frameworks. Traditionally hindcast experiments have been utilized for the evaluation of model performance and the investigation of model biases. In the present paper we demonstrate a broader applicability of the technique that has the potential of bringing weather and climate science communities closer together.

The model well captures the main characteristics of the considered dynamical conditions, including the LLJ to the east of the Tibetan Plateau, in the standard hindcast experiments (Q1.0). In the sensitivity experiments (Q1.5), the lower-tropospheric specific humidity in the LLJ inflow region is increased by an amplitude of $50 \%$. As a consequence, two main competing effects that impact moisture convergence and precipitation formation at the LLJ outflow region can be observed. On the one hand, the increased atmospheric moisture content favors deep convective activity over land areas in southern China. This leads to a lower-tropospheric low pressure anomaly over southeastern China, reduced east-west pressure gradients in the region, and diminished convergence in the LLJ outflow region. On the other hand, the enhanced moisture in the inflow region of the LLJ effectuates, through LLJ moisture transport, changed horizontal humidity gradients in the 

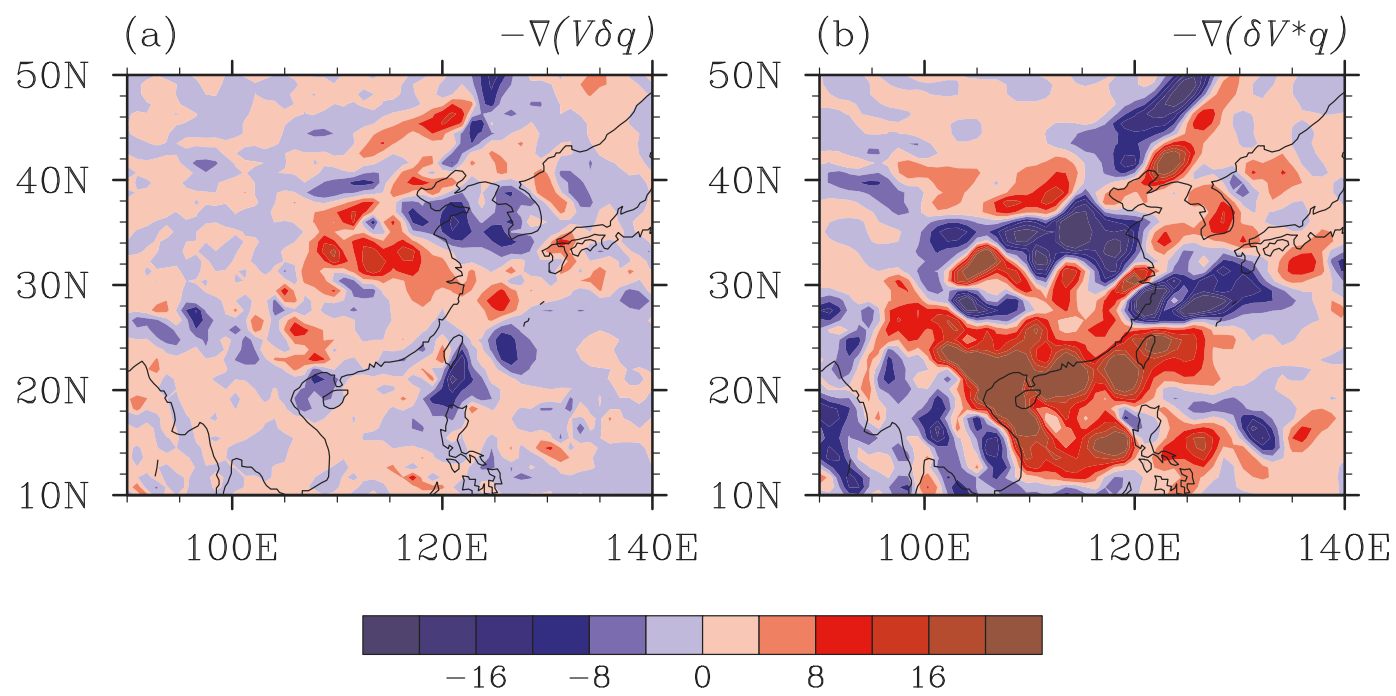

FIG. 16. Decomposition of the changes of horizontal moisture flux convergence $-\langle\overline{\nabla \cdot(\mathbf{v} q)}\rangle$ into (a) $-\langle\overline{\nabla \cdot(\mathbf{v} \delta q)}\rangle$ and (b) $-\langle\overline{\nabla \cdot(\delta \mathbf{v} q)}\rangle$ for the case on $21 \mathrm{Jul} 2012\left(\mathrm{~mm} \mathrm{day}^{-1}\right)$.

LLJ outflow region and consequently reinforced moisture convergence and deep convection formation. For the latter mechanism, the changes in the horizontal moisture gradient are key, while the changes in atmospheric stability or the mechanical uplifting by LLJ-induced convergence are less important for the enhancement of convective activity. Such changes in humidity gradients at precipitation margins are also features that are of central importance when it comes to the simulated response in global warming scenarios (Sherwood et al. 2010)

These results are potentially important in view of possible implications related to climate change for the region. In a warmer world the atmosphere can hold more moisture. The present work suggests increased humidity and a consequently decreased strength of the LLJ may counteract one another to jointly affect moisture flux convergence and precipitation in the outflow region. If the increased humidity transport dominates, then moisture flux convergence and precipitation are reinforced over north China. If the diminished strength of the LLJ dominates, then deep convective activity and precipitation formation may in fact decrease over north China during summer.

Indeed, recent observational studies suggest that summer rainfall in northern China has decreased over the past decades (Zhai et al. 2005; Wei et al. 2008), and that the attributed causes are in line with the mechanisms described in the present work. Weakening eastwest pressure gradients may be responsible for a generally reduced southwesterly flow and moisture convergence in north China during summer (Wang and Zhou 2005). Although the question about the impact of rising temperatures on the hydrological cycle in the region needs further investigation, it is clear that diabatic and dynamic processes are coupled in influencing precipitation formation, and that an appropriate simulation of moisture transport is paramount for GCMs to reproduce the key characteristics of LLJ-related rainfall in the East Asian monsoon region. We plan to pursue the present line of research by conducting convectionpermitting simulations of LLJ-induced heavy rainfall events and investigating the role of convective and boundary layer processes for the initiation of deep convection in more detail. Moreover, the aforementioned climate change aspects of the problem will be addressed in future work as well.

Acknowledgments. A visit of $\mathrm{RC}$ at the Max Planck Institute for Meteorology was made possible through a grant by the joint doctoral promotion program of the Chinese Academy of Sciences and the Max Planck Society. The present study benefited greatly from an original impulse by Cathy Hohenegger and Bjorn Stevens. Technical support by Luis Kornblueh and Sebastian Rast is gratefully acknowledged.

\section{REFERENCES}

Bleeker, W., and M. J. Andre, 1951: On the diurnal variation of precipitation, particularly over central U.S.A, and its relation to large-scale orographic circulation systems. Quart. J. Roy. Meteor. Soc., 77, 260-271, doi:10.1002/qj.49707733211.

Bonner, W. D., 1968: Climatology of the low level jet. Mon. Wea. Rev., 96, 833-850, doi:10.1175/1520-0493(1968)096<0833: COTLLJ $>2.0 . \mathrm{CO} ; 2$

Booth, J. F., S. Wang, and L. Polvani, 2013: Midlatitude storms in a moister world: Lessons from idealized baroclinic life 
cycle experiments. Climate Dyn., 41, 787-802, doi:10.1007/ s00382-012-1472-3.

Brinkop, S., and E. Röckner, 1995: Sensitivity of a general circulation model to parameterizations of cloud-turbulence interactions in the atmospheric boundary layer. Tellus, 47A, 197222, doi:10.1034/j.1600-0870.1995.t01-1-00004.x.

Chen, J. Q., and S. Bordoni, 2014: Orographic effects of the Tibetan Plateau on the East Asian summer monsoon: An energetic perspective. J. Climate, 27, 3052-3072, doi:10.1175/JCLI-D-13-00479.1.

Cook, K. H., and E. K. Vizy, 2010: Hydrodynamics of the Caribbean lowlevel jet and its relationship to precipitation. J. Climate, 23, 14771494, doi:10.1175/2009JCLI3210.1.

Dee, D. P., and Coauthors, 2011: The ERA-Interim reanalysis: Configuration and performance of the data assimilation system. Quart. J. Roy. Meteor. Soc., 137, 553-597, doi:10.1002/ qj.828.

Gill, A. E., 1980: Some simple solutions for heat-induced tropical circulations. Quart. J. Roy. Meteor. Soc., 106, 447-462, doi:10.1002/ qj. 49710644905.

Holton, J. R., 1967: The diurnal boundary layer wind oscillation above sloping terrain. Tellus, 19A, 199-205, doi:10.1111/ j.2153-3490.1967.tb01473.x.

Hoskins, B. J., and D. J. Karoly, 1981: The steady linear response of a spherical atmosphere to thermal and orographic forcing. J. Atmos. Sci., 38, 1179-1196, doi:10.1175/1520-0469(1981)038<1179: TSLROA $>2.0 . \mathrm{CO} ; 2$.

Huffman, G. J., R. F. Adler, M. Morrissey, D. T. Bolvin, S. Curtis, R. Joyce, B. McGavock, and J. Susskind, 2001: Global precipitation at one-degree daily resolution from multisatellite observations. J. Hydrometeor., 2, 36-50, doi:10.1175/ 1525-7541(2001)002<0036:GPAODD > 2.0.CO;2.

, and Coauthors, 2007: The TRMM Multisatellite Precipitation Analysis (TMPA): Quasi-global, multiyear, combined-sensor precipitation estimates at fine scales. J. Hydrometeor., 8, 38-55, doi:10.1175/JHM560.1.

Iacono, M. J., J. S. Delamere, E. J. Mlawer, M. W. Shephard, S. A. Clough, and W. D. Collins, 2008: Radiative forcing by longlived greenhouse gases: Calculations with the AER radiative transfer models. J. Geophys. Res., 113, D13103, doi:10.1029/ 2008JD009944.

Jiang, X., N.-C. Lau, I. M. Held, and J. J. Ploshay, 2007: Mechanisms of the Great Plains low-level jet as simulated in an AGCM. J. Atmos. Sci., 64, 532-547, doi:10.1175/JAS3847.1.

Jin, Q., X.-Q. Yang, X.-G. Sun, and J.-B. Fang, 2013: East Asian summer monsoon circulation structure controlled by feedback of condensational heating. Climate Dyn., 41, 1885-1897, doi:10.1007/s00382-012-1620-9.

Liu, H., M. He, B. Wang, and Q. Zhang, 2014: Advances in lowlevel jet research and future prospects. J. Meteor. Res., 28, 5775, doi:10.1007/s13351-014-3166-8.

Medeiros, B., D. L. Williamson, C. Hannay, and J. G. Olson, 2012: Southeast Pacific stratocumulus in the Community Atmosphere Model. J. Climate, 25, 6175-6192, doi:10.1175/ JCLI-D-11-00503.1.

Mlawer, E. J., S. J. Taubman, P. D. Brown, M. J. Iacono, and A. C. Shephard, 1997: Radiative transfer for inhomogeneous atmospheres: RRTM, a validated correlated-k model for longwave. J. Geophys. Res., 102, 16 663-16682, doi:10.1029/ 97JD00237.

Möbis, B., and B. Stevens, 2012: Factors controlling the position of the Intertropical Convergence Zone on an aquaplanet. J. Adv. Model. Earth Syst., 4, M00A04, doi:10.1029/2012MS000199.

Nordeng, T., 1994: Extended versions of the convective parameterization scheme at ECMWF and their impact on the mean transient activity of the model in the tropics. ECMWF Tech. Memo. 206, 42 pp.

Pincus, R., and B. Stevens, 2013: Paths to accuracy for radiation parameterizations in atmospheric models. J. Adv. Model. Earth Syst., 5, 225-233, doi:10.1002/jame.20027.

Saha, K., 2010: Tropical Circulation Systems and Monsoons. Springer, $324 \mathrm{pp}$.

Saulo, C., J. Ruiz, and Y. G. Skabar, 2007: Synergism between the low-level jet and organized convection at its exit region. Mon. Wea. Rev., 135, 1310-1326, doi:10.1175/MWR3317.1.

Sherwood, S. C., W. Ingram, Y. Tsushima, M. Satoh, M. Roberts, P. L. Vidale, and P. A. O'Gorman, 2010: Relative humidity changes in a warmer climate. J. Geophys. Res., 115, D09104, doi:10.1029/ 2009JD012585.

Stensrud, D. J., 1996: Importance of low-level jets to climate: A review. J. Climate, 9, 1698-1711, doi:10.1175/1520-0442(1996)009<1698: IOLLJT>2.0.CO;2.

Stevens, B., and Coauthors, 2013: Atmospheric component of the MPI-M Earth System Model: ECHAM6. J. Adv. Model. Earth Syst., 5, 146-172, doi:10.1002/jame.20015.

Tiedtke, M., 1989: A comprehensive mass flux scheme for cumulus parameterization in large-scale models. Mon. Wea. Rev., 117, 1779-1800, doi:10.1175/1520-0493(1989)117<1779: ACMFSF $>2.0 . \mathrm{CO} ; 2$.

Wang, B., and I. Orlanski, 1987: Study of a heavy rain vortex formed over the eastern flank of the Tibetan Plateau. Mon. Wea. Rev., 115, 1370-1392, doi:10.1175/1520-0493(1987)115<1370: SOAHRV $>2.0 . \mathrm{CO} ; 2$.

Wang, D., Y. Zhang, and A. Huang, 2013: Climatic features of the south-westerly low-level jet over southeast China and its association with precipitation over east China. Asia-Pac. J. Atmos. Sci., 49, 259-270, doi:10.1007/s13143-013-0025-y.

Wang, Y., and L. Zhou, 2005: Observed trends in extreme precipitation events in China during 1961-2001 and the associated changes in large-scale circulation. Geophys. Res. Lett., 32, L09707, doi:10.1029/2005GL022574.

Wei, F., Y. Xie, and M. E. Mann, 2008: Probabilistic trend of anomalous summer rainfall in Beijing: Role of interdecadal variability. J. Geophys. Res., 113, D20106, doi:10.1029/ 2008JD010111.

Williams, K. D., and Coauthors, 2013: The Transpose-AMIP II experiment and its application to the understanding of Southern Ocean cloud biases in climate models. J. Climate, 26, 3258-3274, doi:10.1175/JCLI-D-12-00429.1.

Zhai, P., X. Zhang, H. Wan, and X. Pan, 2005: Trends in total precipitation and frequency of daily precipitation extremes over China. J. Climate, 18, 1096-1108, doi:10.1175/ JCLI-3318.1. 